\title{
Review
}

\section{Molecular basis of the structure and function of H1 hemagglutinin of influenza virus}

\author{
By Nongluk SriwilaiJaroen ${ }^{* 1, * 2}$ and Yasuo SuzUKI ${ }^{* 2, * 3, \dagger}$
}

(Communicated by Hiroshi KIDA, M.J.A.)

\begin{abstract}
Influenza virus hemagglutinin (HA) contains antigenic sites recognized by the host immune system, cleavage sites cleaved by host proteases, receptor binding sites attaching to sialyl receptors on the target cell, and fusion peptides mediating membrane fusion. Change in an amino $\operatorname{acid}(\mathrm{s})$ in these sites may affect the potential of virus infection and spread within and between hosts. Influenza viruses with H1 HA infect birds, pigs and humans and have caused two of the four pandemics in the past 100 years: 1918 pandemic that killed 21-50 million people ${ }^{1)}$ and 2009 pandemic that caused more than 18,000 deaths. ${ }^{2}$ Understanding the relationship between antigenic structure and immune specificity, the receptor binding specificity in virus transmission, how the cleavage site controls pathogenicity, and how the fusion peptide causes membrane fusion for the entry of influenza virus into the host cell should provide information to find more effective ways to prevent and control influenza.
\end{abstract}

Keywords: influenza, hemagglutinin, antigenic variation, glycan binding, fusion, pandemic

*1 Faculty of Medicine, Thammasat University (Rangsit Campus), Pathumthani, Thailand.

*2 Health Science Hills, College of Life and Health Sciences, Chubu University, Aichi, Japan.

*3 Global COE Program for Innovation in Human Health Sciences, Shizuoka, Japan.

$\dagger$ Correspondence should be addressed: Y. Suzuki, Health Science Hills, College of Life and Health Sciences, Chubu University, Kasugai, Aichi 487-8501, Japan (e-mail: suzukiy@ isc.chubu.ac.jp).

Abbreviations: AM: amniotic membrane; CAM: chorioallantoic membrane; CEF: chicken embryo fibroblast; CMAH cytidine monophospho- $N$-acetylneuraminic acid hydroxylase; CMP-Neu5Ac: cytidine 5 '-monophosphate $N$-acetylneuraminic acid; Gal: galactose; GalNAc: $N$-acetyl-D-galactosamine; Glc: glucose; GlcNAc: $N$-acetyl-D-glucosamine; GD3: Neu5Ac $\alpha 2$ 8Neu5Ac $\alpha 2-3 \mathrm{Gal} \beta 1-4 \mathrm{Glc} \beta 1$-ceramide; HA: hemagglutinin; HBE human bronchial epithelial; HR: heptad repeat; LacNAc: $N$ acetyllactosamine; LSTa: lactoseries tetrasaccharide a ( $\alpha 2$-3-linked sialo-pentasaccharide, Neu5Ac $\alpha 2-3 \mathrm{Gal} \beta 1-3 \mathrm{GlcNAc} \beta 1-3 \mathrm{Gal} \beta 1-4 \mathrm{Glc})$; LSTc: lactoseries tetrasaccharide c $(\alpha 2$-6-linked sialo-pentasaccharide, Neu5Ac $\alpha 2-6 \mathrm{Gal} \beta 1-4 \mathrm{GlcNAc} \beta 1-3 \mathrm{Gal} \beta 1-4 \mathrm{Glc})$; M: matrix protein; MALDI-TOF-MS: matrix-assisted laser desorption/ionization time-of-flight mass spectrometry; MDBK: Madin-Darby bovine kidney; MDCK: Madin-Darby canine kidney; NA: neuraminidase; N-CAM: neural cell adhesion molecule; NEP: nuclear export protein; Neu5Ac: $N$-acetylneuraminic acid; Neu5Gc: $N$ glycolylneuraminic acid; NP: nucleoprotein; NS: non-structural protein; PA: polymerase acidic protein; PB: polymerase basic protein; PC6: proprotein convertase 6; RNP: ribonucleoprotein Sia: sialic acid; SL: sialyl-lactose, 6'SL: Neu5Ac $\alpha 2-6 \mathrm{Gal} \beta 1-4 \mathrm{Glc}$; SLN: $\quad$ sialyl- $N$-acetyllactosamine, $\quad 3$ 'SLN: $\quad$ Neu 5 Ac $\alpha 2-3 \mathrm{Gal} \beta 1$ 4GlcNAc, 6'SLN: Neu5Ac $\alpha 2-6 \mathrm{Gal} \beta 1-4 \mathrm{GlcNAc}$; SREC: swine respiratory epithelial cell; ssRNA: single-stranded ribonucleic acid.

\section{Introduction}

Outbreaks of influenza caused by influenza A viruses have continued to occur in birds and mammals including humans. Each year, seasonal influenza virus infects up to 100 million people worldwide, causing serious illness in 3 to 5 million people and 250,000-500,000 deaths. ${ }^{3)}$ Studies on the antigenic variation of influenza viruses have indicated that they have been continuing to undergo evolutionary changes. All of the subtypes of influenza A virus have been detected in the wild water bird reservoir. ${ }^{4)}$ Avian influenza viruses are maintained among the natural host birds but on rare occasions cross species to infect different animal hosts. In humans, who have no immunity, such an influenza virus of animal origin can lead to a pandemic, usually resulting in significant illness, a large number of deaths, disruption of social life and economic losses. In past century, the world had experienced three pandemics: the 1918 Spanish influenza caused by H1N1 virus, the 1957 Asian influenza caused by H2N2 virus, and the 1968 Hong Kong influenza caused by $\mathrm{H} 3 \mathrm{~N} 2$ virus. In this century, a novel H1N1 virus of swine origin was detected in humans in early April of 2009 and quickly became pandemic (phase 6; 
worldwide spread of human infection) in June 2009 (now called 'pandemic (H1N1) 2009') as a result of highly efficient transmission in humans. This has resulted in continuous circulation of the 2009 pandemic $\mathrm{H} 1 \mathrm{~N} 1$ virus in addition to H3N2 Hong Kong/68 and H1N1 Russian/77 variant viruses among humans. ${ }^{5), 6)}$ This review will focus on H1N1 viruses since they caused both the 1918 and 2009 pandemics (by different strains of an H1N1 subtype) and since the 2009 H1N1 virus is now dominantly circulating in most countries.

Influenza epidemics occur every year and sometimes cause pandemics. The virus undergoes antigenic variation year by year due to the selection of antigenic variants by immunological pressure of the hosts. Genetic reassortment occurs in particular hosts such as pigs concurrently infected with genetically different influenza A viruses, leading to the emergence of a virus with an unprecedented subtype of HA. HA plays a pivotal role in the attachment to and penetration into the host cell (Fig. 1). (A) Once the virus gets into the body, $\mathrm{HA}$ is the main antigenic glycoprotein on the surface of the virus that stimulates host neutralization antibody responses. Therefore, monitoring of antigenic properties and detection of amino acid changes in/around antigenic sites are necessary for the selection of influenza vaccine strains. (B) The virus remains in a noninfectious form until its HA precursor (HA0, Fig. 2a) with a single arginine at the cleavage site is cleaved by host trypsin-like proteolytic enzymes found at respiratory and gastrointestinal tracts into HA1 and HA2 subunits. In the case of HA0 carrying multiple basic amino acids at the cleavage site of some avian strains of $\mathrm{H} 5$ and $\mathrm{H} 7$ subtypes, cleavage occurs by ubiquitous proteases, resulting in systematic viral spread and high mortality in most gallinaceous poultry, e.g., chickens and turkeys. (C) HA mediates virus binding to the specific terminal sialic acid on the cell surface. Detailed characterization of HA binding will provide an insight into the design of an inhibitor interfering with virus binding to host cell receptors that will be useful for therapeutic application. Binding preference of the virus from $\alpha 2-3$ to $\alpha 2-6$ is a prerequisite for transmission of avian viruses to humans. Continuous monitoring of change in the HA gene as well as in the host cell receptor specificity is important to stop these influenza viruses from adapting to humans. (D) The virus bound to its receptor is internalized by endocytosis. (E) In the acidic endosome, the cleaved $\mathrm{HA}$ with a fusogenic domain at the $N$-terminus of HA2 mediates fusion of the host endosomal membrane with the viral membrane, allowing entry of viral ribonucleoprotein into the host cell. Elucidation of the fusion mechanism will be useful for finding agents that can interfere with this function. Therefore, we will review characteristics and functions of HA (H1) to understand how the virus initiates infection and is transmitted and maintained in nature. We hope that this review will provide clues for ways to prevent influenza virus infection by stopping virus replication and mutation, for surveillance of viruses in animal and human populations, for prediction of future epidemic and pandemic threats, and for the development of new vaccines and antivirals.

\section{Hemagglutinin glycoprotein structure}

Influenza A virus, a member of the Orthomyxoviridae family, has a spherical size of about $100 \mathrm{~nm}$ in diameter. As shown in Fig. 2b, it is composed of a lipid bilayer, which is derived from the host plasma membrane, enveloping the ribonucleoprotein (RNP) complex consisting of eight negative sense singlestranded RNA (ssRNA) segments in complex with polymerase proteins (PB1, PB2 and PA) and nucleoprotein (NP). The eight ssRNA segments encode 12 viral proteins. The envelope-associated proteins, hemagglutinin (HA) and neuraminidase (NA), are inserted into the lipid bilayer as spikes. M1 matrix protein is involved in nuclear export and exists beneath the lipid bilayer. M2 proton ion channel is embedded in the lipid bilayer and is involved in $\mathrm{pH}$ maintenance. Polymerase basic protein 1 (PB1) and 2 (PB2) and polymerase acidic protein (PA) form a heterotrimeric RNA-dependent RNA polymerase. Polymerase basic protein 1 frame 2 (PB1-F2), a non-structural protein coded from the second of the three reading frames of the PB1 RNA segment, ${ }^{7)}$ is responsible for pathogenicity. ${ }^{8)} \mathrm{N}$ terminal truncated polypeptide (N40) is a recently found protein that is initially translated at AUG5 of PB1 codon 40 in the mRNA: it appears to interact with the polymerase complex, and loss of its expression can lead to impaired replication. ${ }^{7)}$ Nucleoproteins (NPs) needed for viral replication are associated with vRNA molecules. Non-structural protein NS1 is present in the nucleus of infected cells, ${ }^{9)}$ promoting efficient viral replication and virulence. ${ }^{10)}$ Nonstructural protein 2 (NS2) encoded from the same genetic segment as that for NS1 but with alternative splicing, also called nuclear export protein (NEP) since it contains a leucine-rich nuclear-export signal, ${ }^{11), 12)}$ is bound to M1 protein. ${ }^{13)}$ 


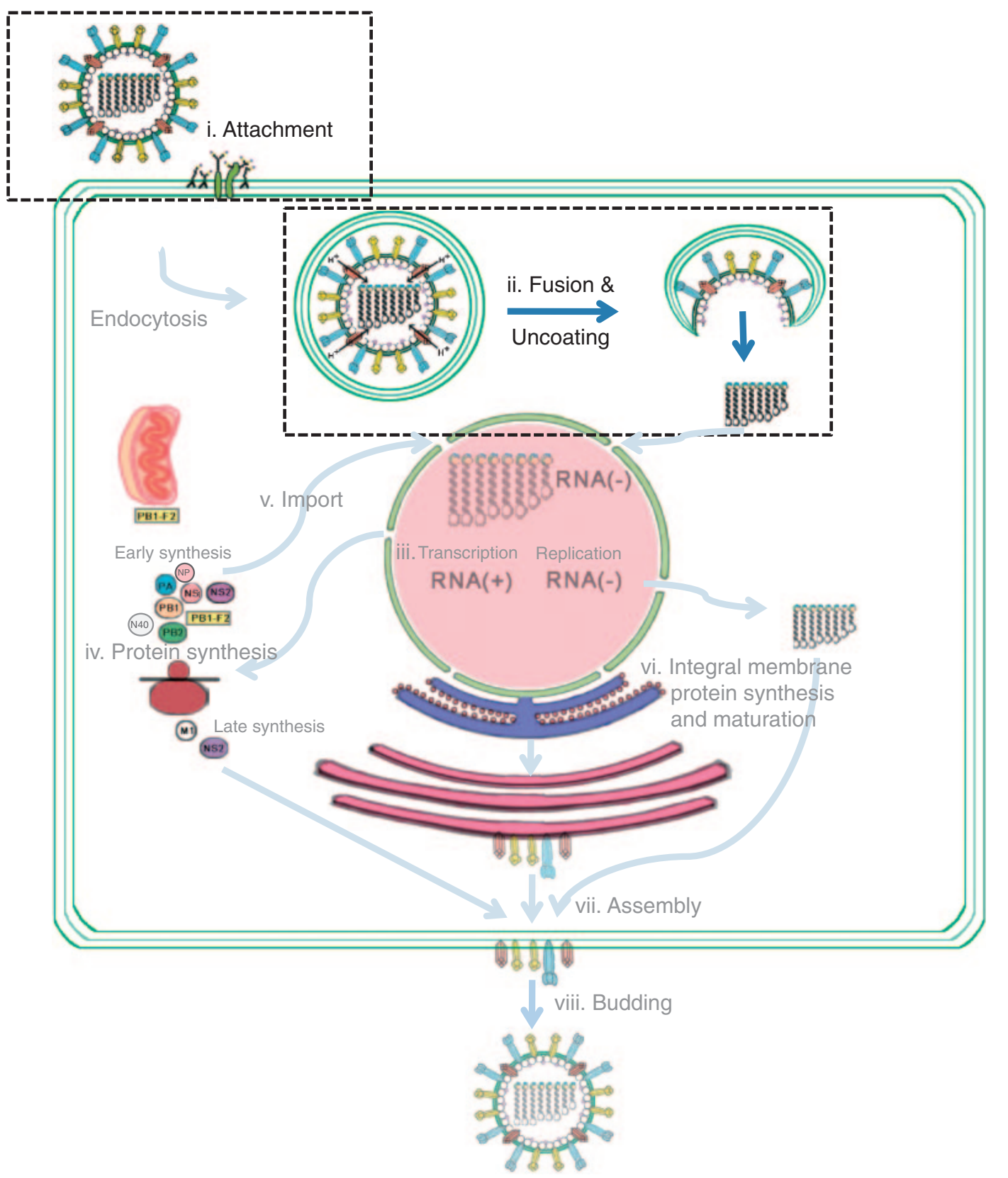

Fig. 1. Influenza virus multiplication life cycle. (i) HA spikes on the viral envelope allow viral entry into the host cell by attaching sialic acid-containing receptors on the host cell membrane. (ii) Following receptor binding and receptor-mediated endocytosis, low $\mathrm{pH}$ in the endosome induces a conformational change in HA resulting in fusion of the viral and endosomal membranes. (iii) This fusion allows viral ribonucleoproteins (vRNPs) to be released into the cytoplasm and enter the host nucleus, where viral transcription and replication occur. (iv) Positive sense mRNAs after transcription and processing are exported and translated using the host-cell machinery in the cytoplasm to produce viral protein components. (v) Viral proteins PB1, PB2, PA and NP making up the vRNP, NS2 (NEP) functioning in control of viral transcription and regulation and vRNP export, ${ }^{132}$ and M1 related to nuclear import and export of $\mathrm{vRNP}^{133)}$ are imported into the nucleus. The NS1 protein is a non-structural protein of a virion that possesses inhibitory activity against host immune responses. ${ }^{10)}$ PB1-F2 localizes to mitochondria and enhances apoptosis. ${ }^{134)}$ (vi) HA, NA and M2 are synthesized on the rough endoplasmic reticulum and matured in the Golgi complex. (vii and viii) The mature glycosylated HA and NA, nonglycosylated M2, NS2-M1-vRNPs, and other M1 and NS2 forming beneath the virus envelope ${ }^{135)}$ are transported to the apical cell membrane, where they are assembled into a progeny virion that finally buds from the host cell surface. Broken boxes represent influenza life cycle steps in which HA spike glycoproteins function and that are explained in detail in this review. 


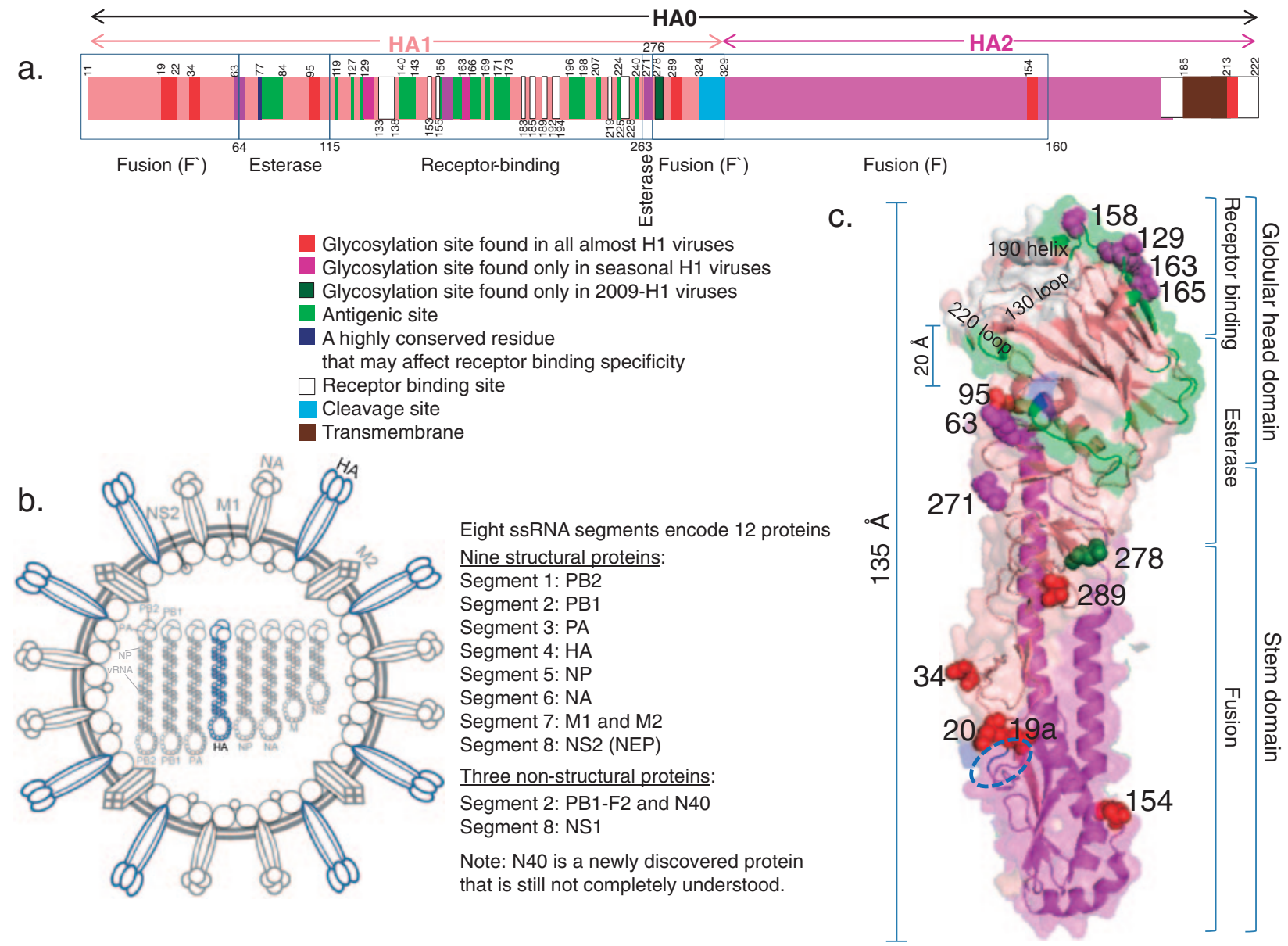

Fig. 2. Structural features of the influenza virus hemagglutinin. a) A drawing of an unfolded polypeptide chain of HA0 of H1 virus, which is composed of HA1 and HA2 containing 3 different regions: (i) fusion (comprised of the $N$ - and $C$-terminal regions of HA1 ( $\mathrm{F}^{\prime}$ subdomain) and HA2 (F subdomain), which are located in the stem domain (Fig. 2c), a main structure responsible for membrane fusion machinery), (ii) esterase (comprised of two subdomains between $\mathrm{F}^{\prime}$ and receptor binding regions, which are located in the middle of folded HA (Fig. 2c)) and (iii) receptor binding (almost in the middle of HA1 of unfolded HA and at the top of folded HA (Fig. 2c)) regions as indicated. b) A schematic of the influenza virus particle. Hemagglutinins are found on the viral surface as trimeric forms coded from a gene segment 4. c) A cartoon diagram of $\alpha$-helices and $\beta$-sheets of HA0 folded into a compact monomer of about $135 \AA$ in length, which is shown in side view (PDB: 1rd8); Salmon, HA1; Warmpink, HA2. Receptor binding site (white) is a pocket made up by 130 loop, 190 helix and 220 loop, located on the top of the globular domain. Amino acid at position 77 (dark blue) in the esterase domain below the receptor binding site of about $20 \AA$ is species-specific, D in avain HAs and E in most human HAs (Fig. 3), suggesting that this residue may correlate with the shift in receptor binding specificity. ${ }^{73)}$ Antigenic sites surround (green) the receptor binding sites (white and dark blue) on the globular domain. Glycosylation sites (spheres) can be found all over the HA molecule of the seasonal H1 viruses (magenta and red spheres). Both 1918-H1 and 2009-H1 pandemic viruses carry glycosylation sites only below the receptor binding site (red sphere), and the 2009-H1 HA has an extra glycosylation site at position 278 (forest green sphere).

Influenza virus HA is coded by RNA segment 4. ${ }^{14)}$ It is cotranslationally translocated across the rough endoplasmic reticulum membrane (RER) (Fig. 1, step vi) and forms a precursor protein, a non-covalent homo-trimer (called HA0). ${ }^{15)}$ Signal peptide (17 amino acids) cleavage and $N$-linked glycosylation occur during the co-translational process. ${ }^{16)}$ Each resultant monomer has a molecular mass of approximately $60 \mathrm{kDa}$ for the unglycosylated form, and its molecular mass increases depending on the number and complexity of $\mathrm{N}$-glycans for the glycosylated form with 549 amino acid residues (Figs. 2a and 3). HA0 is transported through the Golgi complex to the plasma membrane and cleaved by cellular proteases ${ }^{17)}$ (Fig. 1, steps vii and viii) to yield HA1 (327 amino acids) and HA2 (222 amino acids), 

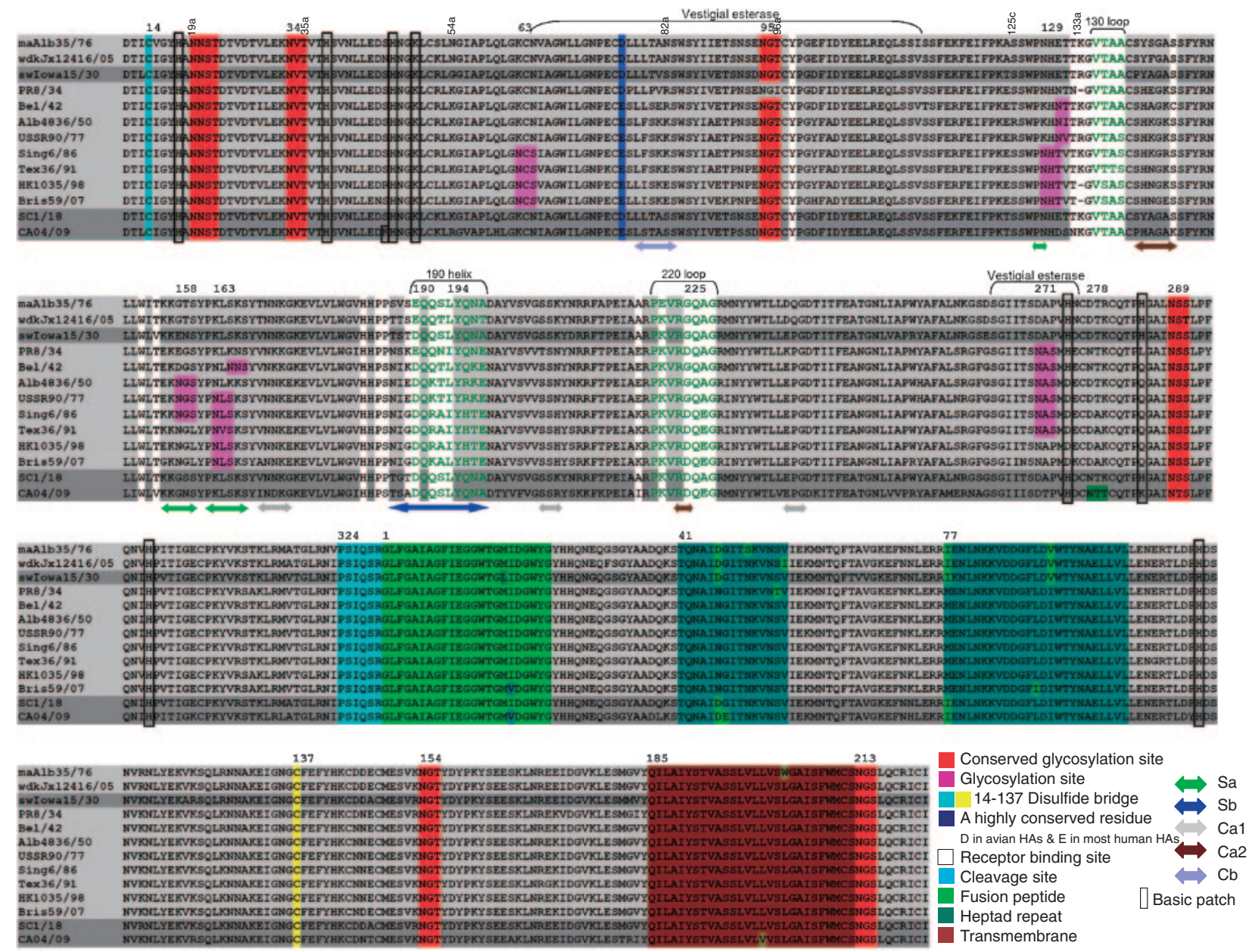

Fig. 3. Comparison of amino acid sequences of HAs of influenza A (H1N1) viruses. The glycosylation sites found in almost all H1N1 viruses are shown in red and those found only in the seasonal H1 HAs are shown in magenta; the glycosylation site in forest color is found only in the pandemic 2009 HA. Antigenic sites are indicated by arrows under the sequences. The residues related to receptor binding are shown in white and blue. Vestigial esterase, 130 loop, 190 helix and 220 loop are indicated in the blankets above the sequences. The basic residues are located in boxes. The cleavage site and fusion peptide are shown in cyan and light green, respectively. The $N$ - (residues 41-55) and $C$ - (residues 77-100) terminal heptad repeats are shown in deepteal; residues that vary between different strains are shown in distinct colors. $\mathrm{C}$ in cyan and $\mathrm{C}$ in yellow form a disulfide bond that links HA1 and HA2. The residues 185 through 212 (crimson) are the transmembrane region.

which are still linked by a disulphide bond; most influenza viruses contain a single basic amino acid residue (arginine, rarely lysine) at the cleavage site. ${ }^{18)}$ The HA glycoprotein of influenza virus is an integral membrane protein (type I transmembrane glycoprotein) that has a cylindrical shape with approximate dimensions of $135 \AA$ (length) $\times 35-70 \AA$ (radius) forming spikes that project externally. ${ }^{19)}$ Each monomer of the HA molecule consists of a globular head domain on a stem domain (Fig. 2c). The globular domain consists of a part of HA1 only (including the receptor-binding domain and vestigial esterase domain), whereas the stem domain contains parts of both HA1 and HA2. ${ }^{20)}$ Amino acid sequences of HA are shown in Fig. 3, and GenBank accession numbers are shown in Table 1. All amino acid numbering of HA throughout this review is based on that of H3 HA. The globular domain consists of HA1 residues $116-261$ folded into a jelly-roll motif of eight stranded antiparallel $\beta$-sheets and into a shallow pocket at the distal tip acting as a receptor-binding site surrounded by antigenic sites. ${ }^{19)}$ The remaining parts of HA1 run down to the stem mainly with $\beta$-sheets. HA2, which is a major part of the stem domain, is folded mainly into a helical coiled-coil structure by which the 80 -A-long helix 
Table 1. Influenza virus hemagglutinins used for analysis

\begin{tabular}{|c|c|c|c|}
\hline Virus/HA & Abbreviation & Protein resource & $\mathrm{PDB}^{*}$ structure \\
\hline A/mallard/Alberta/35/1976 & malAlb76 & BAA01280 & - \\
\hline A/WDK/JX/12416/2005 & WDK05 & CBA17655 & $\begin{array}{l}3 h t p^{89)} \\
3 \operatorname{htq}^{89)}\end{array}$ \\
\hline 1930-swine H1 HA & sw30 & - & $1 r v t^{71)}$ \\
\hline A/swine/Iowa/15/1930 & swIowa30 & ABV 25634 & - \\
\hline A/Puerto Rico/8/1934 (Mount Sinai) & huPR34 & AAM75158 & $\begin{array}{l}\operatorname{lrvz}^{71)} \\
\operatorname{lrvx}^{71)}\end{array}$ \\
\hline A/Bellamy/1942 & huBel42 & $\mathrm{ABD} 62843$ & - \\
\hline A/Albany/4836/1950 & huAlb50 & $\mathrm{ABP} 49316$ & - \\
\hline A/USSR/90/1977 & huUSSR77 & $\mathrm{ABF} 21277$ & H1N1 $1977^{31)}$ \\
\hline A/Singapore/6/1986 & huSing86 & ABO38395 & - \\
\hline A/Texas/36/1991 & huTex91 & AAP34322 & - \\
\hline A/Hong Kong/1035/1998 & huHK98 & AAK70453 & - \\
\hline A/Brisbane/59/2007 & huBB07 & ACA28844 & - \\
\hline 1918-human H1 HA precursor (HA0) & - & - & $\operatorname{1rd} 8^{118)}$ \\
\hline A/South Carolina/1/1918 & huSC18 & AAD17229 & $\operatorname{1ruz}^{71)}$ \\
\hline A/Brevig Mission/1/1918** & huBM18 & - & $2 \mathrm{wrg}^{130)}$ \\
\hline A/California/04/2009 & huCA09 & ACP41105 & - \\
\hline Influenza viral $\mathrm{HA}$ at the $\mathrm{pH}$ of membrane fusion & - & - & $1 \mathrm{htm}^{131)}$ \\
\hline
\end{tabular}

*PDB: protein data bank; **A/Brevig Mission/1/1918: huBM18 HA contains one nucleotide different from huSC18 HA, but this different nucleotide provides different codons that code for the same amino acid; — : not used in this review.

forms the stem backbone. HA2 contains the hydrophobic peptide required for membrane fusion that is in a trimer interface far (about $35 \AA$ ) from the bottom of the molecule. A part of HA2 is a long helical chain with 28 amino acids anchored in the membrane followed by a 10-residue cytosolic tail. ${ }^{20)} \mathrm{N}$-linked oligosaccharides, which affect HA functions, are found both in globular and stem regions. The glycosylation sites appear to have a large variation in the globular head region of HA1 but to be more conserved in the stem region of HA1 and HA2. ${ }^{21)}$

\section{Antigenic change in hemagglutinin}

$\mathrm{HA}$ is the major viral antigen inducing a neutralizing antibody response. Due to high replication rates but poor proofreading ability of a viral RNA polymerase, ${ }^{22)}$ progeny viruses with a mutated genome are generated and subsequently proliferate if environmental conditions are favorable for their survival; hence, progeny viruses that are most suitable for the environment, such as existing immunity, would become the predominant population. Consequently, the surviving viruses with mutated HAs (antigenic variation) have the potential to escape neutralization by a vaccine and antibody induced by prior infection and have the ability to reinfect human populations. ${ }^{23)}$ This explains the continuous occurrence of influenza annually and indicates the need for annual vaccine updates. The other feature of influenza A virus responsible for rapidly generating viral genetic diversity and being a particularly worrisome zoonotic threat is its segmented genome that facilitates reassortment between different strains of influenza A virus mixed in the same host, such as a pig susceptible to both human and avian influenza viruses, probably resulting in an influenza virus that is new in human populations. The new influenza virus with HAs able to bind to human-type receptor and new to human immunity may create a global pandemic (worldwide epidemic).

Virus strains in all previous influenza pandemics, including 1918 (H1N1), 1957 (H2N2), 1968 (H3N2) and 2009 (H1N1), have the ability not only to efficiently transmit between humans but also to introduce new antigenic properties into humans. 
Although the HA sequence patterns of the 1918 pandemic and 2009 pandemic viruses are similar, they were caused by different H1N1 subtype viruses. ${ }^{24)}$ It remains unclear whether the source of the 1918 pandemic, well known as 'Spanish flu', was direct avian-to-human transmission or involvement of an intermediate host. ${ }^{25)}$ Within a few years after the pandemic hit, the 1918 pandemic strain became to settle, causing annual epidemics with gradual antigenic variation and lowered death rates; epidemic H1N1 viruses that originated from the 1918 pandemic are called 1918-derived H1N1 viruses. By 1957, the 1918-derived H1N1 viruses had disappeared from human circulation but can still be detected in pigs. However, human 1918-derived H1N1 viruses reemerged from a laboratory in 1977 and have been circulating continuously. ${ }^{26)}$ In general, the H1N1 2009 pandemic, the first influenza pandemic of the 21st century, is believed to have emerged through pigs and to have jumped to humans. Genetic analysis of the pandemic (H1N1) 2009 viruses showed that they were genetic reassortants between two unrelated swine viruses: six of the eight gene segments from the avian/human/swine triple-reassortant North American swine virus lineage and two gene segments (NA and M) from the Eurasian avian-like swine virus lineage; thereby, the H1N1 2009 virus is a 'quadruple' reassortant. ${ }^{27)}$ Although three gene segments encoding for NP, NS and HA proteins in the $2009 \mathrm{H} 1 \mathrm{~N} 1$ viruses share a remote common descent from the 1918 virus with the seasonal H1N1 virus, the 2009 $\mathrm{H} 1 \mathrm{~N} 1$ virus is different from the seasonal $\mathrm{H} 1 \mathrm{~N} 1$ virus; for example, the $2009 \mathrm{HA}$ has antigenicity that is sufficiently distinct from that of the seasonal H1N1 virus to induce a different immune response. ${ }^{25), 28)}$ However, when the 2009 H1N1 pandemic emerged and became the predominant strain, circulating 1918derived seasonal H1N1 viruses started to decrease and subsequently seem to have rapidly disappeared from humans. ${ }^{5)}$ On August 10, 2010, it was announced that the $2009 \mathrm{H} 1 \mathrm{~N} 1$ pandemic had ended, but the progeny virus continued to circulate as a seasonal influenza virus (post-pandemic period), resulting in the 2009-derived seasonal H1N1 virus lineage, which has circulated endemically and epidemically in humans. It is expected that the novel $\mathrm{H} 1 \mathrm{~N} 1$ virus will continue to evolve in humans in a similar way that the $1918 \mathrm{H} 1 \mathrm{~N} 1$ virus did and become seasonal strain with antigenicity different from that of its original pandemic virus. ${ }^{29)}$

A better understanding of the HA evolution and variation is a prerequisite for improving the strategy for control of influenza by vaccination. Based on data from analyses of the HA sequence variation from natural isolates causing epidemics and from analyses of HA mutations by growing the virus with monoclonal antibodies, 5 antigenic sites (antibody-recognizing sites) were identified on HA (Figs. 3 and 5). They were designated as Sa (residues 128-129, 156160, 162-167) and Sb (residues 187-198), which are located near the spike tip; Ca1 (residues 169-173, 206-208, 238-240) and Ca2 (residues 140-145, 224225), which are between adjacent HA monomers (subunit interface) about halfway down the globular head; and $\mathrm{Cb}$ (residues 74-79), that is within the vestigial esterase domain near the base of the globular head (S: strain-specific; C: common), surrounding the receptor binding pocket as shown in Fig. 2c. ${ }^{30)}$ Substitutions of amino acids at these antigenic sites during infection are associated with antigenic change. A comparison of amino acid sequences of influenza $\mathrm{H} 1$ viruses isolated from different hosts in different years demonstrated that H1N1 viruses isolated from pigs in 1930 (early classical swine influenza viruses) show antigenicity similar to that of the 1918 pandemic virus with different amino acids only at S159N in the Sa site, G188S in the Sb site, D225G and S140P in the $\mathrm{Ca} 2$ site and $\mathrm{A} 77 \mathrm{~V}$ in the $\mathrm{Cb}$ site, suggesting that they share a common ancestor. ${ }^{28), 29)}$ Early isolated seasonal human H1N1 viruses, such as huPR34 and huBel42 strains, still carry the same amino acids in the $\mathrm{Sa}$ and $\mathrm{Sb}$ sites as those in the 1918 virus. Substantial antigenic variation of seasonal H1N1 viruses was found in the late 1940s before the influenza A (H2N2) pandemic in 1957. ${ }^{29), 31)}$ The 1977 H1N1 viruses were genetically almost identical to the early 1950 s viruses; in the antigenic regions, only amino acid positions at 165 in Sa and 194 in Sb are different between huAlb50 and huUSSR77. Thus, it has been believed that the 1950 viruses kept in a freezer were released and reintroduced in the human population. ${ }^{32)}$ Further antigenic evolution (variation) of the $1977 \mathrm{H} 1 \mathrm{~N} 1$ viruses has occurred in humans, resulting in the present $\mathrm{H} 1 \mathrm{~N} 1$ viruses, which are different from the original 1918 viruses: 23 amino acid substitutions are found in 50 amino acids constructing the epitopes in the 5 antigenic sites on the HA of huBB07 in comparison with those on the HA of huSC18. ${ }^{31)}$ In April 2009, a new reassortant swineorigin $\mathrm{H} 1 \mathrm{~N} 1$ virus was detected in Mexico, and it became a pandemic in June 2009 and has continued to spread as a seasonal influenza virus since August 2010 as mentioned above. The HA gene of this 2009 
virus shares similar amino acid residues in antigenic sites with those of the 1918 virus, which differ in only 10 amino acid residues: S159N in Sa site, G188S and T189A in Sb site, V169I, N171D and K209R in Ca1 site, S140P, Y141H and S145K in Ca2 site, and L75S in $\mathrm{Cb}$ site. ${ }^{25), 31)}$ Vaccines made from 1918-like and classical swine H1N1 viruses cross-protect against the $2009 \mathrm{H} 1 \mathrm{~N} 1$ virus in mice and humans and vice versa. ${ }^{33), 34)}$

H1N1 virus was first identified in pigs in the United States in 1930 and has continued to circulate in pig populations by passage to young susceptible (non-immune) pigs, causing economic losses. The classical swine H1N1 viruses from 1930 to 1990s were shown to be antigenically conserved. This slow evolution of influenza viruses in pigs is probably because they have little immune pressure; due to the short life span, the viruses are maintained in nonimmune pigs. ${ }^{28)}$ Swine H1N1 viruses can also be transmitted to other animals such as ferrets, turkeys, ${ }^{35)}$ cats and humans. ${ }^{36), 37)}$

The primal source of all influenza A viruses is wild aquatic birds, and these birds that are infected with the virus are usually asymptomatic. ${ }^{38)}$ Avian influenza viruses occasionally cause epidemics in poultry through infected feces or nasal or salivary excretions. ${ }^{39)}$ Antigenic sites on the HA of avian viruses are highly conserved, probably due to less complexity of the bird immune system. ${ }^{29)}$ Transmission of $\mathrm{H} 1 \mathrm{~N} 1$ viruses from humans to pigs (known as human-like swine viruses) and vice versa ${ }^{36), 40)}$ and transmission of $\mathrm{H} 1 \mathrm{~N} 1$ viruses from birds to pigs (avian-like swine viruses) and vice versa ${ }^{41)}$ have been reported, and pigs are thus thought to be a potential mixing vessel to create a new virus with a novel HA antigen that may infect immunologically naïve humans. HA sequences of the 1918 and 2009 pandemic viruses, which were transmitted from animals to humans, are similar and they are different from seasonal H1 HAs. The difference in antigenicity between the HAs of human origin and animal origin is probably due to the different immune pressures in animals and humans.

Comparison within five antigenic sites showed that there were remarkable changes at $\mathrm{Sb}$ sites located at the tip of HA in all HA variants. ${ }^{30)}$ In addition to variations of amino acid sequences in antigenic sites, amino acid substitutions associated with acquisition of glycans near the antigenic sites interfere with host immune system surveillance. The presence of glycosylation sites (Asn-X-Ser/Thr, where $\mathrm{X}$ is any amino acid except Pro) is thought to mask the protein surface from recognition by an antibody because glycans are host-derived and thus not immunogenic in the host. ${ }^{42)}$ It appears that huSC18 HA has only one $N$-glycosylation site in the globular head domain at N95 near Ca2, whereas seasonal $\mathrm{H} 1 \mathrm{~N} 1$ viruses have gradually acquired up to four glycosylation sites, N95 near the Ca2 region and N129 or N131, N158 and/or N163 or N165 in the conserved Sa region, to achieve shielded antigenic sites for escaping the pre-existing immunity in hosts previously exposed to a less glycosylated antigen. ${ }^{24), 31)}$ Similar to the pandemic 1918 virus and early strains circulating in the 1930 s, the 2009 virus has no glycosylation site around position 129 or position 163 and has only a single glycosylation site at position 95. ${ }^{31)}$ It has been expected that a new epidemic strain of the 2009 virus will acquire not only amino acid substitutions in the antigenic regions but also additional glycosylation sites to avoid targeting by antibodies. ${ }^{31)}$ Recent data have shown that there are altered amino acids in antigenic sites of HAs of pandemic (H1N1) 2009 isolates obtained in India during the period from May 2009 to October 2010: N129D, K157E and N159D in Sa; S188T/I and L194I in Sb; G173E, S206T/A, R208K and E238K in Ca1; and H141Y, A144S and D225G/N in Ca2. Two of these Indian isolates have one of two substitutions, $\mathrm{S} 165 \mathrm{~N}$ and $\mathrm{K} 172 \mathrm{~T}$, resulting in additional $\mathrm{N}$-glycosylation sites at 165 in Sa and 170 in Ca1. ${ }^{43)}$ Accurate prediction of antigenic changes is important for production of an influenza vaccine for the next season.

\section{Receptor binding specificity of hemagglutinin}

Influenza A viruses do not bind to or infect cells treated with neuraminidase, which catalyzes removal of sialic acid residues. ${ }^{44}$ The binding to and viral penetration into cells can be restored by re-sialylation of the cells. ${ }^{45}$ ) These findings lead to the conclusion that sialic acid is an essential component on the host cell surface for influenza A virus infection. Sialic acids (Sias) are a class of nine-carbon acidic amino monosaccharides (5-amino-3,5-dideoxy-D-glycero-Dgalacto-2-nonulosonic acid: neuraminic acid (Neu)) usually found at the outermost ends of $\mathrm{N}$-glycans, $\mathrm{O}$ glycans, and glycosphingolipids (gangliosides) that are involved in a broad range of biological processes, such as cell proliferation, apoptosis and differentiation. ${ }^{46)}$ In nature, Neu derivatives can be stabilized by acylation of the amino group at the C-5 position with an acetyl or glycolyl group, giving Neu5Ac or Neu5Gc, respectively (Fig. 5a). ${ }^{47)}$ Neu5Ac and 
Neu5Gc are the most common forms of more than 50 types of sialic acid. Their distribution varies among tissues and animal species. Neu5Gc is found in most mammalian cells including cells in the respiratory tract of pigs ${ }^{48)}$ and primary swine respiratory epithelial cells (SRECs). ${ }^{49}$ The HAs of all H1N1 swine-adapted viruses typically containing V155 or I155 have increased binding affinity for Neu5Gccontaining receptors. ${ }^{50)}$ However, Neu5Gc is found in healthy human cells less than $0.1 \%$ of total Sias ${ }^{51)}$ obtained only directly from nutrition due to an exon deletion/frameshift mutation in the human CMPNeu5Ac hydroxylase ( $C M A H)$ gene encoding CMAH required to transfer an oxygen atom to CMP-Neu5Ac for generation of CMP-Neu5Gc. ${ }^{52)}$ The lack of Neu5Gc production may render cells less susceptible to some infections, such as infection with enterotoxigenic Escherichia coli K99 ${ }^{53)}$ and the malaria parasite Plasmodium reichenowi. ${ }^{54)}$ However, this infection-resistant mechanism in humans cannot protect cells from influenza infection because both Neu5Ac and Neu5Gc can be recognized by influenza $A$ viruses and most influenza $A$ viruses preferentially recognize Neu5Ac over Neu5Gc. ${ }^{55)}$ V155 was detected in pandemic (H1N1) 2009 viruses but not in previous H1N1 human viruses, suggesting that this novel H1N1 strain in the human population may acquire V155T in the near future (Fig. 3).

Different influenza virus strains display clearly different preference for sialyl linkages at the C-2 position catalyzed by specific sialyltransferases: human and classical swine influenza viruses prefer to bind sialic acids attached to galactose by $\alpha 2-6$ linkage, ${ }^{55), 56)}$ whereas avian and equine viruses prefer sialic acids with $\alpha 2-3$ linkage instead; Fig. 5b shows the chemical structures of sialic acids with $\alpha 2-6$ and $\alpha 2-3$ linkages. ${ }^{56), 57)}$ These binding specificities have been believed to relate to glycan distribution on infection sites. By lectin binding studies and/or matrix-assisted laser desorption/ionization time-offlight mass spectrometry (MALDI-TOF-MS) analyses, tissues of different animals and different tissues or cells within individual animals were shown to express different sialyloligosacharide isomers. Alpha 2-6 sialylated isomers are predominant in the human upper respiratory tract, but $\alpha 2-3$ isomers are present in the lower respiratory tract of humans. ${ }^{58), 59)}$ There is an increase in $\alpha 2-6$ receptor expression compared with $\alpha 2-3$ expression from the upper and lower parts of the porcine trachea towards the porcine lung, ${ }^{48)}$ and $\alpha 2-6$ linkages rather than $\alpha 2-3$ linkages are abundantly expressed in SRECs. ${ }^{49)}$ Alpha 2-3 and 2-6 linkages are found on the intestinal epithelium of chickens and quails ${ }^{60), 61)}$ and in lung and embryo cells of chickens and ducks. ${ }^{62)}$ Alpha 2-3 receptors are found predominately in avian enteric tracts. ${ }^{63)}$ The ability of the virus to bind to receptors on host cells is regarded as a primary indicator of its potential to transmit among hosts. For example, the classical H1 swine influenza viruses become adapted to grow in the allantoic cavity of embryonated chicken eggs by increased binding activity to Sia $\alpha 2-3 \mathrm{Gal}$ receptors, which predominately exist in the allantoic cavity, ${ }^{64}$ ) after passages in the eggs. ${ }^{65)}$

Not only two types of glycosidic linkages between Sia and Gal of terminal glycans, $\alpha 2-3$ and $\alpha 2-6$ linkages, which are well-known principal receptors targeted by avian and human influenza HAs, respectively, but also $\alpha 2-8$ linkage found on many glycoproteins (e.g., neural cell adhesion molecules (N-CAMs)) and some gangliosides (e.g., GD3 (Neu5Ac $\alpha 2-8$ Neu 5 Ac $\alpha 2-3 \mathrm{Gal} \beta 1$-4Glc $\beta 1$-ceramide (Fig. 5b)) have been shown to be bound by some influenza $A$ viruses including reassortant A/NWS/ $33^{66)}$ and A/California/04/09. ${ }^{67)}$

Modifications of inner parts of glycan receptors, such as sulfation, fucosylation and sialylation, at the second (Gal) or third (GlcNAc or GalNAc) sugar of the terminal trisaccharide (Sia-Gal-GlcNAc/ GalNAc-) have been shown to affect receptor binding of some influenza A viruses; for example, a human A/New York/1/18 virus (having dual $\alpha 2-3$ and $\alpha 2-6$ binding specificity) had reduced ability to bind to $\alpha 2-6$-linked Sia but increased affinity for $\alpha 2-3$-linked Sia that carried an additional negative charge, either sulfate or sialic acid group at the third sugar (GlcNAc) of the terminal trisaccharide. ${ }^{68), 69)}$ A/Mexico/INDRE4487/09 and A/Texas/15/09 pandemic H1N1 viruses isolated from patients with severe upper respiratory tract infection and fatal infection, respectively, have been reported to preferentially bind $\alpha 2-6$-linked Sia and have the capacity for binding to $\alpha 2-3$-linked Sia with fucosylation of the third sugar, GlcNAc (Fig. 5b). ${ }^{70)}$ Sulfated glycans, 6-O-Su-3'SLN (Fig. 5b), found in human airway mucins could prevent attachment of these influenza viruses to target cells. ${ }^{68)}$ Fucose was found at GlcNAc on position 3 of the terminal trisaccharide of some $N$ glycans in human upper respiratory tissues, ${ }^{69)}$ whereas fucose only at the initial GlcNAc of the $N$-glycan core connected to Asn was detected in porcine respiratory tissues, ${ }^{48)}$ intestinal tracts of the chicken and quail, ${ }^{60)}$ and chorioallantoic and amniotic membranes of embryonated chicken eggs. ${ }^{64)}$ 
In addition, glycan chain length depending on the number of $N$-acetyllactosamine units (LacNAc; $\left.[\mathrm{Gal}(\beta 1-4) \mathrm{GlcNAc}]_{\mathrm{n}}\right)$ was thought to influence receptor binding of influenza A viruses, as discussed below. ${ }^{69)}$

The HA1 subunit, which carries a receptor binding site, is responsible for attachment of the virus to specific sialyl sugar chains on the host cell surface. Changes in amino acid residues in the receptor binding region of HA can cause alteration of influenza binding preference. Evidence from molecular replacement and crystallographic statics demonstrated that the sialic acid binding site of $\mathrm{H} 1$ viruses is located in amino acid positions of 111 to $265^{71)}$ at the distal tip of each monomer of the HA trimer, which is formed by three secondary structures: one helix (190-helix, residues 190-198) and two loops (130-loop, residues 135-138; and 220-loop, $221-228)^{71)}$ at the edges of each HA monomer (Fig. 2c).

Substitution of amino acids in the HA receptor binding region of $\mathrm{H} 1$ viruses and a receptor binding specific assay revealed that two amino acid residues at positions 190 and 225 in HA1 are critical as determinants of receptor binding specificity, by which H1 HA carrying E190 and G225 preferentially binds to $\alpha 2-3$ receptors in avians, and $\mathrm{H} 1 \mathrm{HA}$ possessing D190 and G225 favors both $\alpha 2-3$ and $\alpha 2-6$ receptors in pigs, whereas H1 HA containing D190 and D225 effectively binds to $\alpha 2-6$ receptors in humans (Fig. 6). ${ }^{68), 72), 73)} \mathrm{A}$ shift of the preferential receptor-binding specificity from 'avian' to 'human' type seems to be a prerequisite for the creation of a human pandemic. All five 1918 H1N1 viruses from the Spanish influenza pandemic have D190 but differ at position 225; A/New York/1/18 and A/London/ 1/19 carry G225 identical to swine viruses and an avian virus adapted to pigs, whereas A/South Carolina/1/18, A/Brevig Mission/1/18 and A/ London/1/1918 have an additional change from $G$ to $\mathrm{D}$ at position 225 . These findings suggest that change of amino acid at position 190 (E to D) is likely to be the minimal change allowing the shift from binding to avian type receptors to binding to human type receptors. ${ }^{74}$ This is supported by a finding that double mutations at E190D and D225G in huSC18 HA that changed binding preference from human to avian type receptors (called AV18 mutant) resulted in abolishment of viral transmission between ferrets; ${ }^{72)}$ there are similarities in virulence, pathology and immune response to influenza virus infection between humans and ferrets. ${ }^{75)}$
Analyses of HA-glycan cocrystal structures indicated that Y98, S/T136, W153, H183 and L/ I194, which are highly conserved among the different HA subtypes, are involved in anchoring Neu5Ac and, thus, the specificity of binding is governed by interaction of the $\mathrm{HA}$ receptor binding site with the asialo portion including the glycosidic oxygen atom and sugars next to the Neu5Ac residue (Fig. 6). ${ }^{69)}$ PDB structural information used for analysis in this review is shown in Table 1 . Interaction of the receptor binding site on the HA of 1930-swine H1 virus (sw30) with pentasaccharide Neu5Ac $\alpha 2$ 6Gal $\beta 1-4$ GlcNAc $\beta 1-3 \mathrm{Gal} \beta 1-4 \mathrm{Glc}$ (LSTc; Fig. 6a, left column) used as a human receptor analog (PDB: 1rvt) is shown in umbrella-like topology in Fig. 6a, middle column. ${ }^{71), 76)}$ This cocrystal structure is superimposed with huBM18 HA (PDB: 2wrg). These data indicated that there are two critical sets of HA amino acid residues interacting with long $\alpha 2-6$ receptors: (1) K222, D225 and Q226 provide crucial contacts with the base region, the Neu5Ac $\alpha 2$ 6Gal $\beta 1$ - motif and (2) D190, Q192 and S193 make optimal contacts with the extension region, the $-4 \mathrm{GlcNAc} \beta 1-3 \mathrm{Gal} \beta 1-4 \mathrm{Glc}$ motif. The HA of sw30 contains D225G, which provides only the backbone carbonyl oxygen of glycine $(\mathrm{G})$ positioned to interact with the Gal sugar in the base region but lacks extra contact of the side chain ${ }^{68)}$ (Fig. 6a, right column). Receptor binding studies demonstrated that H1N1 human viruses have higher binding affinity for Neu5Ac $\alpha 2-6 \mathrm{Gal} \beta 1-4 \mathrm{GlcNAc}$ (6'sialyl $(N$-acetyllactosamine), 6'SLN) than that for Neu5Ac $\alpha 2-6 \mathrm{Gal} \beta 1$ 4Glc (6'sialyl-lactose), 6'SL) ${ }^{77)}$ and that this binding preference of $6^{\prime}$ SLN over $6^{\prime}$ SL can be abolished by a single mutation of $190,{ }^{78)}$ suggesting that D190 plays a key role in contact with GlcNAc. E190D and/or G225E/D mutations were also shown to increase binding affinity of avian H1 HAs for $6{ }^{\prime S L N}{ }^{79)}$ The HA of the pandemic $2009 \mathrm{H} 1 \mathrm{~N} 1$ virus, huCA09, has K222, D225 and Q226 in contact with the base region and D190, Q192 and S193 in contact with the extension region of the LSTc human receptor. Additionally, huCA09 HA has K133a (K133a in huSC18; R133a in swIowa30), unique K145 (S145 in HA1 of the other H1N1 viruses) and K156 (K156 in huSC18 and swIowa30) that make a positively charged lysine fence: K133a, K145 and K222 are positioned to anchor the Neu5Ac $\alpha 2-6 / 2-3 \mathrm{Gal}$ base, whereas K156 provides optimal contacts with sugars beyond the extension region of the LSTc receptor. ${ }^{80)}$ It has been proposed that amino acid residues around the receptor binding site affect virus binding to the 
human receptor, including (i) I219 and E227 influencing orientation of the residue at position 186, which is a part of an interaction network with D190 ${ }^{81}$ ) and (ii) T200 interacting with Q191 in the 190-helix. ${ }^{82)}$ These residues in HA1 of the new H1N1 viruses would be changed to be adapted to humans; receptor binding evidence demonstrated that double mutations of T200A and E227A provided strong binding to the human receptor. ${ }^{82)}$

Human-adapted HAs bind with high affinity to long $\alpha 2-6$ glycans containing a tandem $N$-acetyllactosamine structure such as Neu5Ac $\alpha 2-6 \mathrm{Gal} \beta 1$ $4 \mathrm{GlcNAc} \beta 1-3 \mathrm{Gal} \beta 1-4 \mathrm{GlcNAc}^{83)}$ in umbrella-like topology, whereas avian HAs and swine HAs prefer to bind to short sialylated glycans such as Neu5Ac $\alpha 2$ $3 \mathrm{Gal} \beta 1-4 \mathrm{GlcNAc}$ (for avian HAs) and Neu5Ac $\alpha 2$ $6 \mathrm{Gal} \beta 1-4 \mathrm{GlcNAc}$ (for swine HAs) in cone-like topology. ${ }^{69), 81)}$ Determination of precise structures of $N$-glycans, which are required for sufficient viral infection into host cells, ${ }^{84)}$ showed that $N$-glycans derived from amniotic membrane (AM) cells and chorioallantoic membrane (CAM) cells of chicken embryonated eggs used for growing influenza viruses and $N$-glycans isolated from the porcine trachea and lungs consist of terminal short sialylated trisaccharide structures, Sia-Gal( $\beta 1-4)$ GlcNAc-, but not a long tandem $N$-acetyllactosamine structure. ${ }^{48)}$ In contrast, $\mathrm{N}$-glycans derived from human bronchial epithelial (HBE) cells, which are representative upper respiratory ciliated epithelial cells, showed the presence of long sialylated glycans, Sia-[Gal $(\beta 1-4) G l c N A c$ $(\beta 1-3)] n .^{69)}$

The correlation between these glycan features and results of $\mathrm{HA}$ binding studies suggested that adaptation of influenza viruses to bind to sialylated glycans of a characteristic umbrella-like topology may be an additional factor for sufficient viral transmission between humans. The pandemic 2009 influenza viruses possess D at both positions 190 and 225 and were shown to bind to not only short but also long $\alpha 2-6$ receptors. ${ }^{85)}$ D225 variants of the HA of pandemic (H1N1) 2009 viruses have been reported. $225 \mathrm{E}$ variants were detected in both severe and mild cases with similar frequencies, whereas $225 \mathrm{G}$ and $225 \mathrm{~N}$ variants were detected only in severe cases; thereby, $\mathrm{G}$ or $\mathrm{N}$ in this position may be associated with severe human respiratory disease. ${ }^{86), 87)}$ In vitro single mutation from $\mathrm{D}$ to $\mathrm{G}$ at position 225 of the pandemic (H1N1) 2009 HA resulted in maintenance of the binding affinity for $\alpha 2-6$ receptors with increase in the binding affinity for $\alpha 2-3$ receptors and increase in viral binding to macrophages and type II pneumocytes in the alveoli and to tracheal and bronchial submucosal glands in human respiratory tissues. ${ }^{88)}$

The crystal structures of HAs of huPR34 ${ }^{71}$ ) and WDK05 ${ }^{89)}$ interactions with trisaccharide Neu5Ac $\alpha 2-3 \mathrm{Gal} \beta 1-3 / 4 \mathrm{GlcNAc}$ demonstrated two key amino acids, E190 and Q226 (highly conserved in $\mathrm{H} 1 \mathrm{~N} 1$ viruses), that make optimal contacts of HAs with the cone-like topology (Fig. 6b, middle column). HAs of avian viruses with E190 favor $\alpha 2-3$ glycans, ${ }^{90}$ ) and E190D mutation found in swine and human HAs has poor electron density for $\alpha 2-3$ linkage due to disruption of the Q226 position required for its interactions with glycosidic oxygen and the 4-OH group of Gal-2. ${ }^{91)}$ Human-adapted influenza virus HAs preferring $\alpha 2-6$ over $\alpha 2-3$ linkage not only provide the potential to bind to receptors on the human respiratory epithelial surface but also prevent them from entrapment by human bronchial mucin, which is rich in Sia $\alpha 2-3 \mathrm{Gal}$ branches. ${ }^{91), 92)}$

Glycans (Fig. 4) on the globular head of HA shield antigenic sites from accessibility of antibodies, and due to location of the antigenic sites near the receptor binding site, these glycans influence HA binding to host cell receptors. Effects of glycans on the sialic acid-binding site are related to the number of glycans, location within HA and its structure. ${ }^{42)}$ Most studies have shown an inverse relation between the number and complexity of glycans near the receptor binding pocket in the HA head and the binding affinity: HA binding affinity for its specific ligand increases as $N$-glycans become less complex $^{21), 93)}$ or have disappeared. ${ }^{93)}$ The complexity and compostion of $\mathrm{N}$-glycans on the HA molecule are host cell-dependent. ${ }^{42), 94)}$ More bulky $N$-glycans on the HA of MDCK-grown viruses than on the HA of egg-grown viruses were observed even though the HAs from both sources have identical sequences of amino acids. ${ }^{95)}$ In general, MDCK-grown viruses were found to have lower receptor binding activity than that of their egg-grown counterparts. ${ }^{78)}$ These findings suggested that the bulky $N$-glycans on the viral HA sterically interfere with virus-receptor interaction. In addition, glycosylation is site-specific, glycan structures at the same site on the HA molecule are very similar, and the glycan size decreases as the distance of the site from the viral envelope increases. ${ }^{96)}$ Moreover, sequence data indicated that there are no glycosylation sites on the receptor binding apex of the HAs of avian strains, swine strains, and both the 1918 and 2009 pandemic strains (Fig. 3). Human-adapted H1N1 viruses usually have 
1918 HA: H47, K50, H275, H285 and H298 Seasonal HA: K50, $\mathrm{H} 47$ and $\mathrm{H} 298$ 2009 HA: K46, H47, K50, H275, K285 and H298

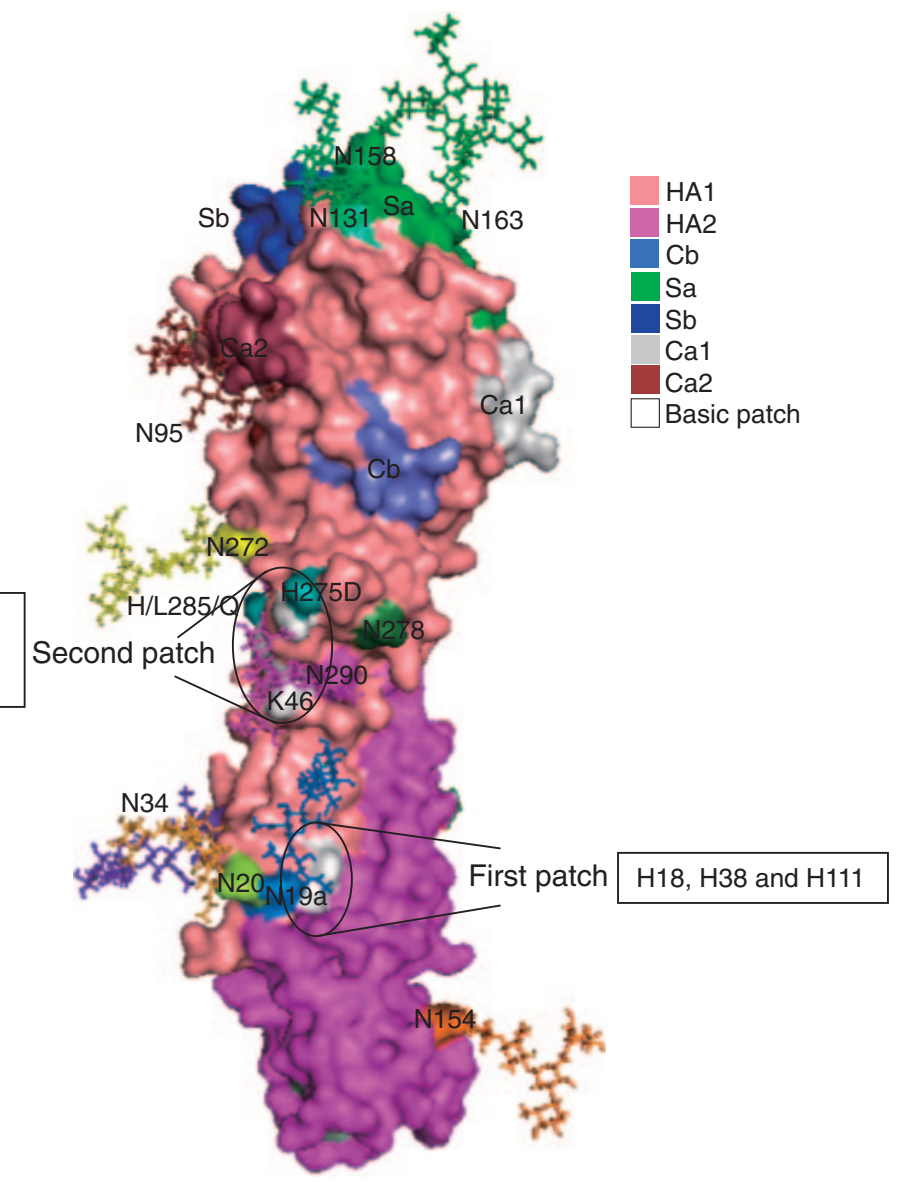

Fig. 4. Schematic surface diagram of antigenic sites, basic patches and glycosylation sites of an H1 HA monomer (PDB code H1N1 1977 from Igarashi et al..). ${ }^{31)}$ Five antigenic sites, Sa (green), Sb (blue), Ca1 (gray), Ca2 (chocolate) and Cb (slate), are located at the tip ( $\mathrm{Sa}$ and $\mathrm{Sb}$ ), halfway down (Ca1 and $\mathrm{Ca} 2$ ) and at the base $(\mathrm{Cb})$ of the $\mathrm{HA} 1$ globular head. The first basic patch and the second basic patch are in the solid line ellipse. The first one is situated near the cleavage site, whereas the second is located at the base of the HA1 globular domain. There are three conserved basic residues (HA1: His18 and His38; HA2: His111) in the first patch and 6 possible basic residues (HA1: His47, His275, His/Lys285, His298, Lys46 and Lys50) in the second patch. Residues in cyan indicate nonbasic residue mutations found in most seasonal H1 HAs. Glycosylation sites are distributed over the entire H1 monomer. From 1918, H1 HAs that circulated in humans showed a tendency towards more glycosylation sites. Glycosylation sites (such as N19a, N131, N158, N163, N95 and N290) near or in antigenic regions and/or basic sites could interfere with immunity and infectivity. N278 (green) is an extra glycosylation site found only in the pandemic 2009 H1 HAs. $N$-glycans were added in silico into the H1N1 1977 3D protein structure using GlycoProt.

an additional glycosylation site(s) at residues 131/ 129 and/or 165 or 158 and/or 163 (H3 numbering). These data suggested animal species-related differences in HA glycosylation. ${ }^{29), 97)}$

\section{Membrane fusion mediated by hemagglutinin}

During the early stage of the influenza life cycle, the virus must fuse the viral membrane with the host membrane to release the viral genetic material into host cells for its replication (Fig. 1). Uncleaved HAs (HA0) are unable to fuse the membranes, and HA0 of influenza viruses therefore needs to be cleaved into two subunits, an HA1 head and an HA2 stalk, by a host protease, in which the generated $N$-terminal HA2 fusion peptide (20-25 first residues of HA2) is buried into the interior of the molecule at neutral $\mathrm{pH}$ (Fig. 7a and 7b). ${ }^{98), 99)}$ Cleavage of HA0 possessing a single arginine at the cleavage site occurs during viral budding or infection by a secreted or membranebound host trypsin-like protease, such as plasmin or tryptase, ${ }^{100)}$ which is located only at certain sites in the body, generally on mucosal surfaces of the respiratory and gastrointestinal tracts. ${ }^{101)}$ These host proteases are therefore determinants of the viral 
Neu

a.<smiles>NC(C(=O)O)[C@@H]1OC(O)(C(=O)O)CC1(O)[C@H](O)[C@H](O)CO</smiles>

b. Terminal sialic acid linked to:

Neu5Ac<smiles>CC(=O)NC1[C@H](O)[C@@H]2OC(O)(C(=O)O)C[C@]1(O)[C@H]2O</smiles>

Neu5Gc

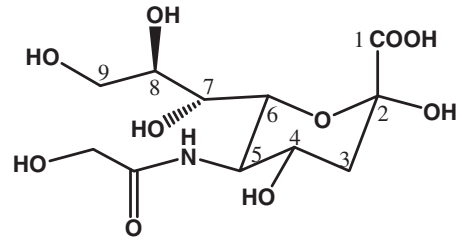

Glycoproteins: via a covalent bond to serine/threonine ( $O$-linked) or asparagine $(N$-linked)
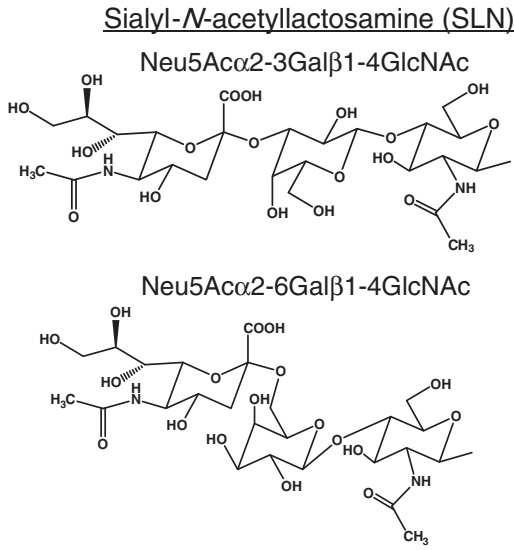

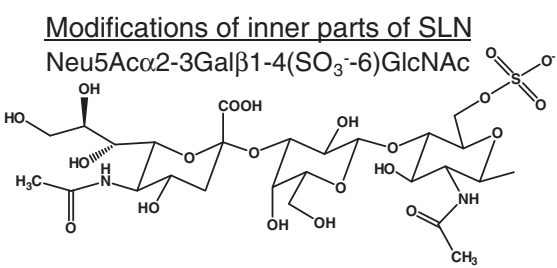

Neu5Ac $\alpha 2-3 G a l \beta 1-4(F u c \alpha 1-3)$ GIcNAc

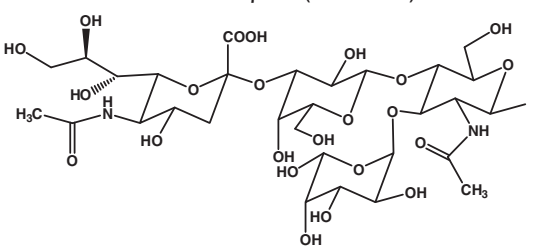

Synthetic glycopolymer

Sialyl-lactose (SL)

Neu5Ac $\alpha 2-6 \mathrm{Gal} \beta 1-4 \mathrm{Glc}$

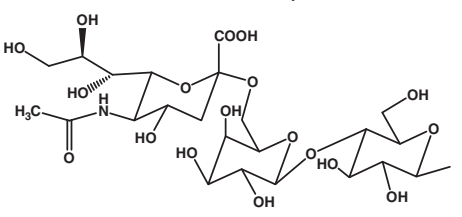

Found in human milk

\section{Glycolipids}

Gangliosides

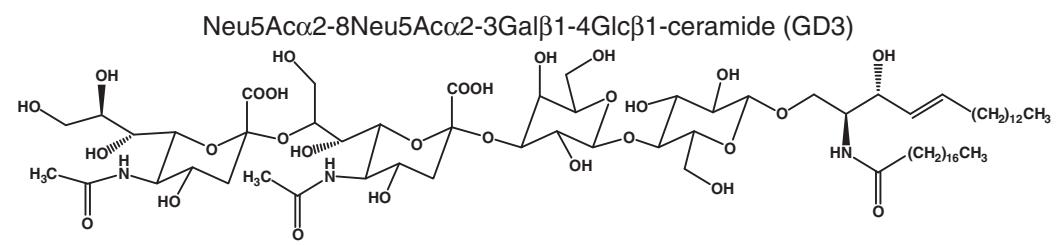

Fig. 5. Chemical structures of (a) the common molecular species of sialic acids and (b) some terminal sialo-sugar chains bound by some influenza $\mathrm{A}$ viruses as mentioned in the text.

replication sites. In contrast, HA0 with a series of basic amino acids Arg-X-Arg/Lys-Arg or its derivatives, where $\mathrm{X}$ is a non-basic amino acid at the proteolytic cleavage site, which is found in certain avian strains (common to highly pathogenic $\mathrm{H} 5$ and $\mathrm{H} 7$ viruses arising by mutation of low pathogenic $\mathrm{H} 5$ and $\mathrm{H} 7$ progenitors in poultry), is cleaved intracellularly in the trans-Golgi compartment by ubiquitous proteases that recognize the multibasic motif, such as furin (a subtilisin-like endoprotease) and proprotein convertase 6 (PC6), present in a wide range of different host cells; hence, the highly pathogenic influenza viruses cause systemic lethal infection ${ }^{102), 103)}$ with a high mortality rate up to $100 \%$ in poultry. ${ }^{104)}$ Passage of influenza viruses in either cell cultures or chicken embryo cells in the presence of a non-trypsin-like protease with neutral cleavage site specificity, chymotrypsin, elastase or thermolysin, resulted in replacement of a basic amino acid (Arg) at the HA0 cleavage site by a neutral amino acid, such as Ile, Thr or Met, depending on the substrate specificity of those proteases. Such mutant viruses contained HA0s that were resistant to trypsin activation but could be activated by the respective protease in different cell types, and they were apathogenic for chickens. ${ }^{100)}$ These findings suggested that the HA proteolytic cleavage site correlates with viral infectivity, tropism and pathogenicity. ${ }^{99), 105)}$

After the binding of HA1 to sialic acid receptors either in $\alpha 2-3$ or $\alpha 2-6$ linkages, the virus is taken up (endocytosis) into an endosome. As shown in Fig. 7b, at low $\mathrm{pH}$ inside the endosome, the cleaved HA undergoes a drastic conformational change, in which the HA1 head domain becomes detrimerized and separates from the HA2 fusion domain, except for a disulfide bridge linked between residues 14 and 137, and the HA2 domain undergoes two major structural 

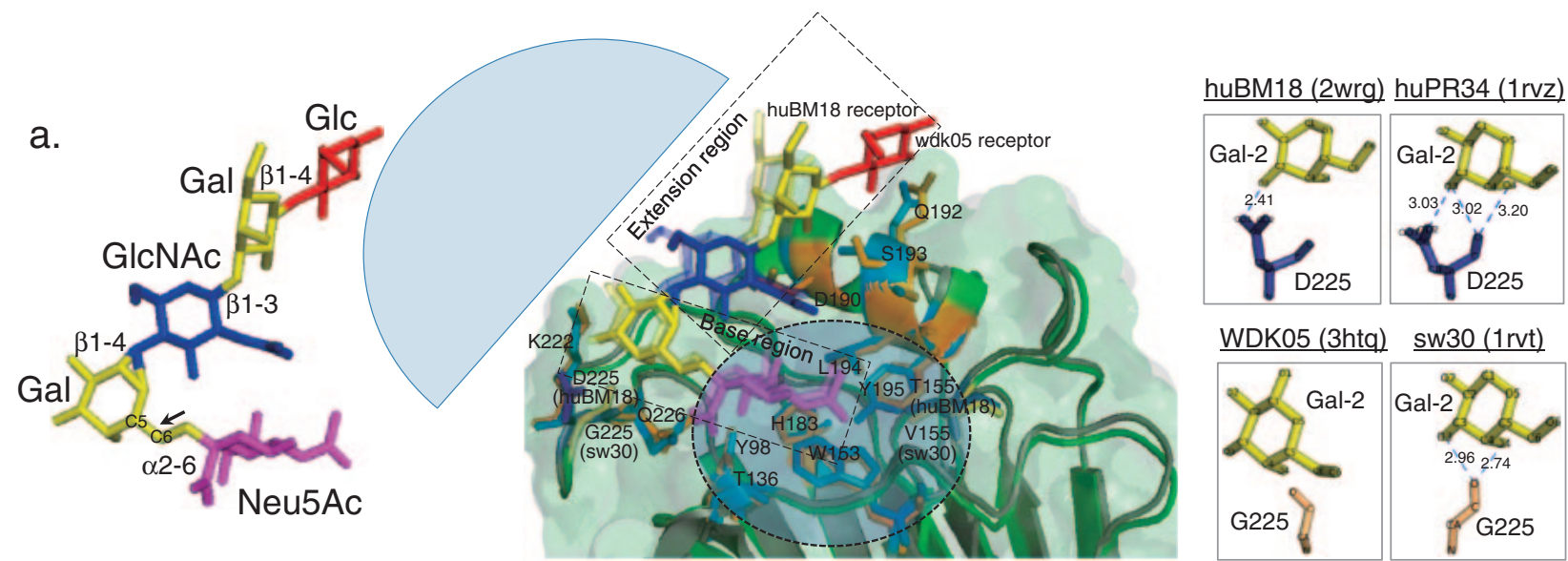

WDK05 (3htq) sw30 (1rvt)

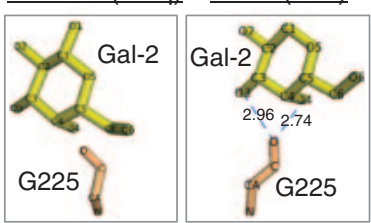

b.
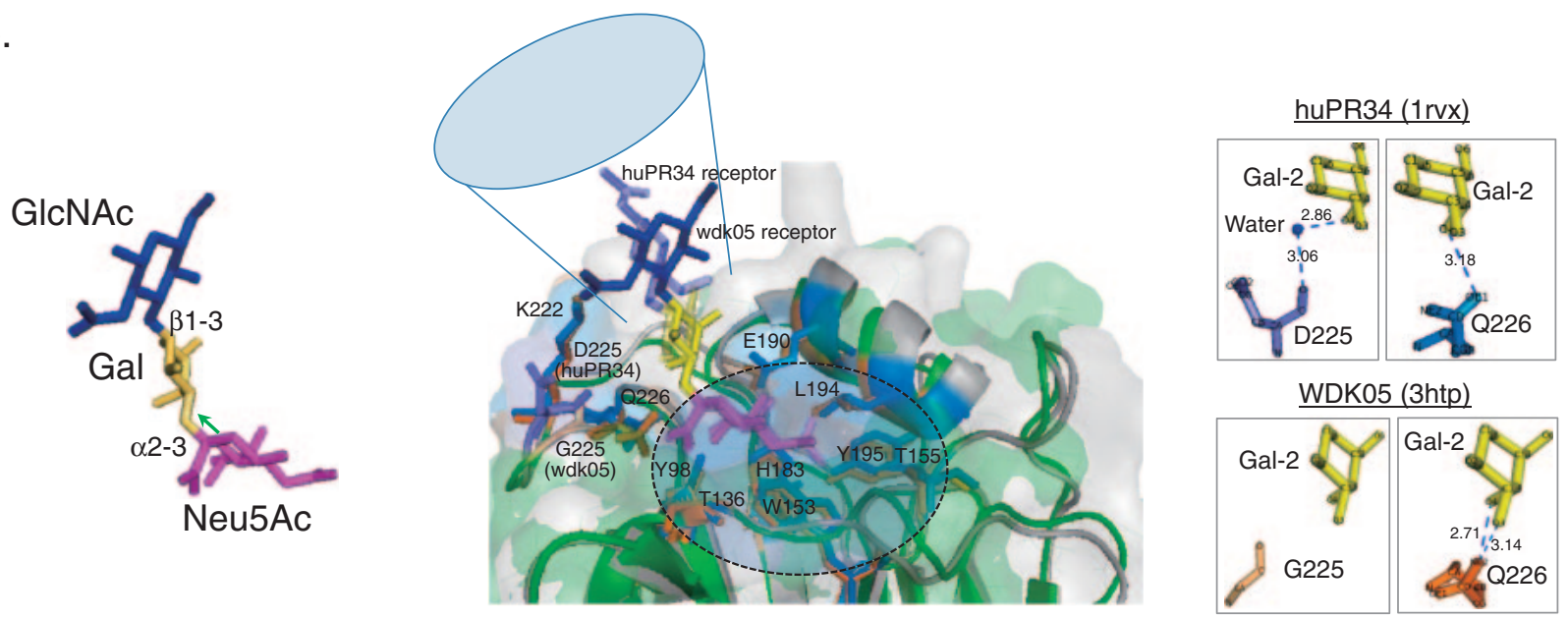

Fig. 6. Structures of human- and avian-type receptors and their interactions with the H1 receptor binding site (modified from Chandrasekaran et al., 2008). ${ }^{69)}$ Left panel: Structures of human $\alpha 2-6$-linked (Neu5Ac $\alpha 2-6 \mathrm{Gal} \beta 1-4 \mathrm{GlcNAc} \beta 1-3 \mathrm{Gal} \beta 1-4 \mathrm{Glc}$ (LSTc), upper pannel) and avian $\alpha 2$-3-linked (Neu5Ac $\alpha 2-3 \mathrm{Gal} \beta 1-3 \mathrm{GlcNAc}$, which is a sialyl-neo- $N$-acetyllactosamine part of LSTa, lower pannel) sialic acid receptors. Black (pointing up) and green (pointing down) arrows indicate cis- and trans-conformations, respectively, which generate low-energy conformations of $\alpha 2-6$ - and $\alpha 2$-3-linkages, respectively, in their specific binding pockets of HAs. Middle panel: Interactions between sialic acid receptor analogs and H1 HAs. a) Superposition of H1 HAs of huBM18 (PDB code $2 \mathrm{wrg}$ ) in gray and sw30 (PDB code 1rvt) in green complexed with LSTc. b) Superimposition of the receptor binding sites of WDK05 HA (PDB code $3 \mathrm{htp}$ ) in green and huPR34 HA (PDB code 1rvx) in gray in complex with Neu5Ac $\alpha 2-3 \mathrm{Gal} \beta 1-3 / 4 \mathrm{GlcNAc}$. Right panel: Interactions between amino acid residue(s) at position(s) 225 and/or 226 of the HA of influenza A (H1N1) viruses indicated at the top and Gal-2 sugar. PDB codes are in parentheses. Numbers on the dashed lines are the bond distance between two atoms in angstroms.

rearrangements that are (i) a loop-to-helix transition in the $N$-terminal part of HA2 at amino acid positions 55-76 resulting in extension of the coiled coil and (ii) a helix-to-loop transition of amino acids at positions 106-112 in the central coiled coil of HA2 resulting in inversion of all structural entities in the $C$-terminal part of HA2 by 180 degrees. These rearrangements lead to the formation of an extended intermediate; the $N$-terminal hydrophobic fusion peptide is extruded from a hydrophobic pocket in the spike near the viral membrane to the endosomal membrane, whereas the $C$-terminal transmembrane anchor of HA2 remains in the viral membrane. The extended intermediate collapses by zipping up $N$ - and $C$ terminal membrane anchors together. This collapse drives hemifusion (fusion of the outer leaflets of the two membranes) and formation of a fusion pore (Fig. 8). ${ }^{98), 106)}$

The structure of the fusion peptide critical for viral fusion function has been characterized in detail. It is short with 23 amino acid residues composed of several large hydrophobic residues and several 
a.

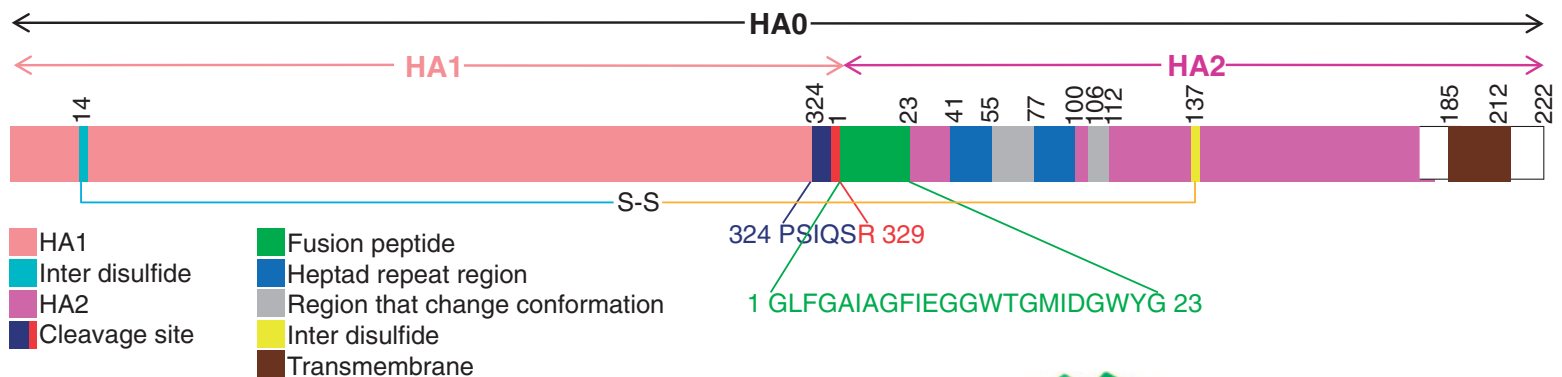

b.
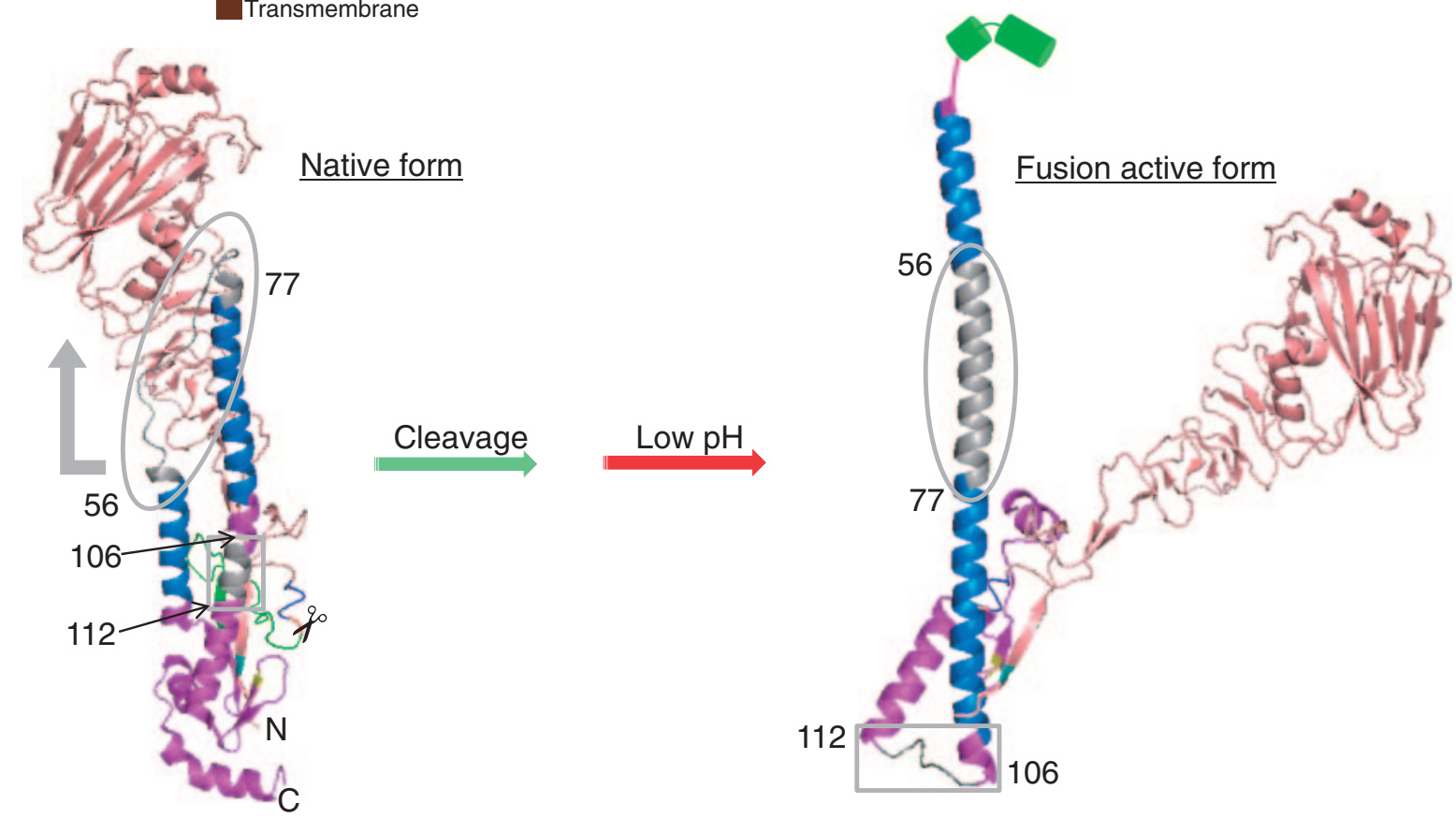

Fig. 7. Conformational changes of influenza HA structure at the $\mathrm{pH}$ of membrane fusion. a) Primary structure of HA0 protein showing a disulfide bridge (S-S) linked (cyan and yellow line linkage) between HA1 (salmon) and HA2 (magenta), cleavage site (dark blue and red), fusion peptide (green), heptad repeat regions (marine), conformational change regions when HA is in acidic $\mathrm{pH}$ (gray) and transmembrane domain (chocolate). b) Tertiary structure of an HA monomer is cleaved between R329 (red) and 1G (green) into a fusion-competent HA1-S-S-HA2 form and unfolds in an acidic environment leading to conformational change. HA2 in the absence of HA1 refolds to the fusion-active form. The fusion peptide (green) pops out and then moves toward and is inserted into the host endosomal membrane, leading to membrane fusion. Colors indicated in a) correspond to those in b).

glycine residues interspersed throughout the sequence. The hydrophobicity and helical structure have generally been believed to be responsible for interaction and membrane destabilization by perturbing regular lipid packing. ${ }^{107)}$ The fusion peptide sequence 1GLFGAIAGFIEGGWTGMIDGWYG23 is extremely well conserved in H1N1 viruses, except amino acids in bold being M17L substitution in sw30 and I18V substitution in hu07 and pdm09 (Fig. 3). Comparison of the H1 HA fusion peptide sequence with those of the other 15 recognized subtypes revealed that there are variations only at $12 \mathrm{G} / \mathrm{N}$, $15 \mathrm{~T} / \mathrm{Q} / \mathrm{E} / \mathrm{S} / \mathrm{P}, 17 \mathrm{M} / \mathrm{L}, 18 \mathrm{I} / \mathrm{V}$ and $\left.19 \mathrm{D} / \mathrm{A} / \mathrm{N}^{106}\right)$ The small and apolar residue Gly, which is highly conserved between HA strains and is located at the $N$-terminus of HA2, has been shown to be a key amino acid necessary for fusion. Deletion of this residue $(\mathrm{G} 1)^{108), 109)}$ or site-directed mutations from Gly1 to either Val (G1V) or Glu (G1E) ${ }^{110}$ ) completely abolished membrane fusion and viral infectivity, whereas a mutation from Gly4 to Glu (G4E) resulted in less efficient membrane fusion. ${ }^{111)}$ The NMR structure of G1V, which caused a complete fusion defect, showed an irregular approximately linear amphipathic helix but with replacement of Gly1 with Ser (G1S), which can lead to hemifusion (lipid mixing) but not to fusion pore formation (content mixing) and can form a normal amphipathic 


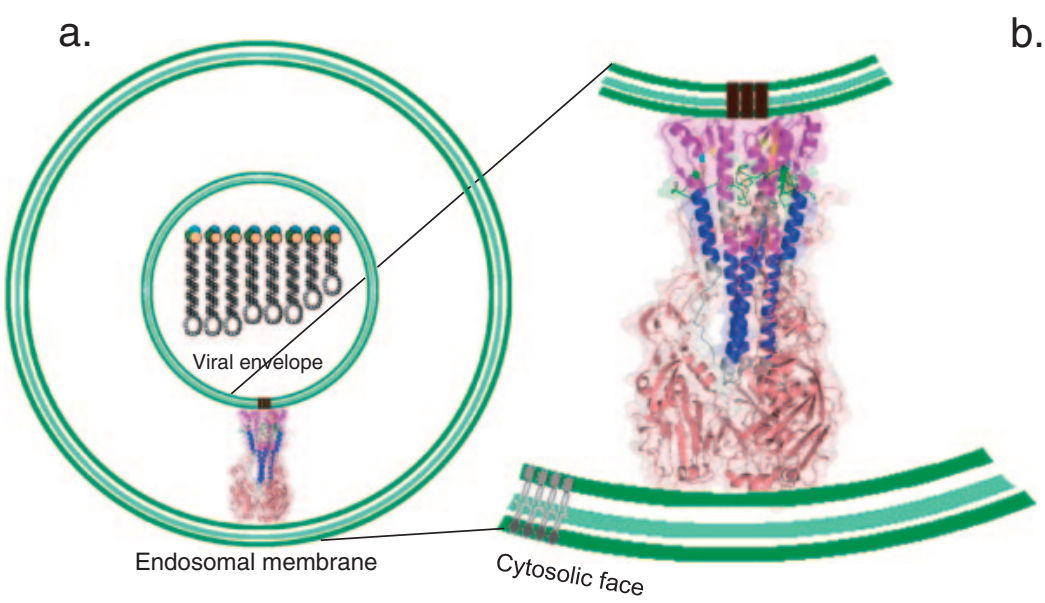

b.

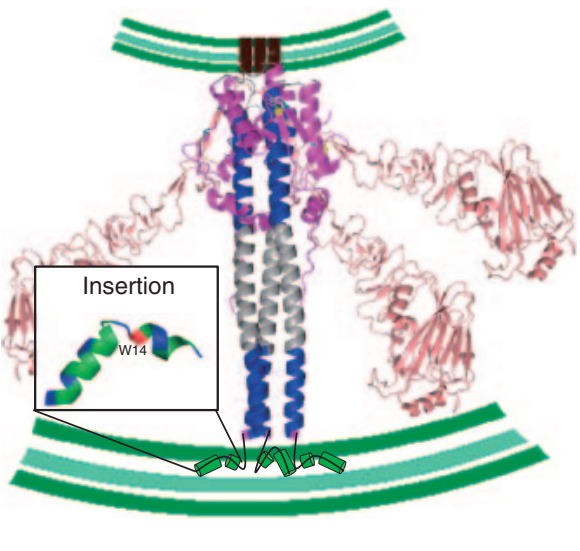

C.

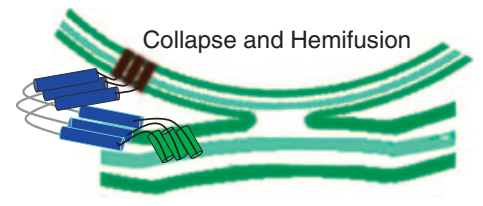

d.

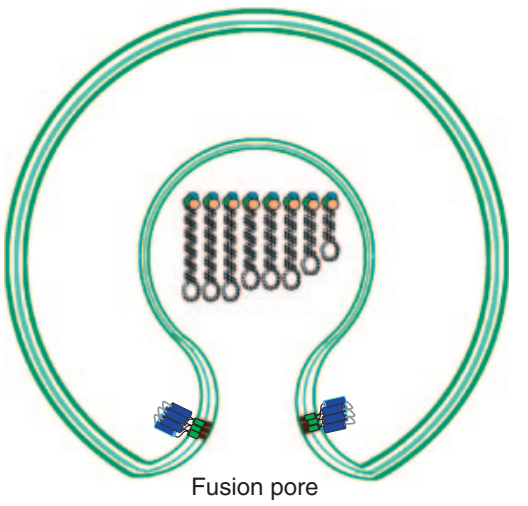

Fig. 8. Consequences of membrane fusion by influenza HA. a) In the pre-fusion state, the fusion peptides (green) at the $N$-terminus of HA2 are sequestered in the interior of the structure (PDB code 1ruz). b) Following proteolytic cleavage at HA2 arginine residue 329, the acidic environment induces conformational changes resulting in removal of the HA1s and exposure of fusion peptides (PDB code $1 \mathrm{htm})$. Since the fusion peptides are hydrophobic, they interact with the bilayer membrane (extended intermediate state) by folding into a boomerang-shaped structure for tight interactions with the membrane. In the inset, the kink of the boomerang structure required for membrane fusion is stabilized by a tryptophan (W) residue at HA2 position 14 (red). c) Further conformation rearrangements in HA2 lead to apposition of the viral envelope and endosomal membrane (collapse of the extended intermediate). When the two bilayers come into contact, they induce hemifusion, d) making bilayers open into a fusion pore (fusion pore formation state). After HA2 rearranges until it is fully symmetric, the pore cannot be resealed (post-fusion state).

boomerang (V-shaped) structure (Fig. 8b, inset) but cannot form a smooth glycine ridge on the $N$-terminal arm of the boomerang-shaped molecule. These findings indicated the importance of an angled and deeply membrane-inserted boomerang structure for hemifusion and the importance of a glycine ridge for driving the hemifusion into a full fusion pore. ${ }^{110), 112)}$ Substitution of a highly conserved Glu11 with either Gly (E11G) or Val (E11V) provided a mutant HA with fusion efficiency similar to that of the wild-type HA. ${ }^{111), 113)}$ The residue Trp14 is also highly conserved and its mutation to Ala (W14A) completely blocked fusion; double electron-electron resonance spectroscopy showed that the W14A mutant has a very flexible angle between the two arms of the boomerang. This indicated that the large Trp residue plays a critical role in stabilization of the kink in the boomerang structure that is required for hemifusion. ${ }^{114)}$ Further studies on fusion activities of fusion peptide mutants are necessary for a better understanding of the fusion mechanism.

About 18 amino acids next to the fusion peptide sequence are heptad repeat (HR) regions (Fig. 3) consisting of a repeating pattern of seven amino acids as follows: Hydrophobic, Polar, Polar, Hydrophobic, Charged, Polar, and Charged residues. The HR pattern in the HA2 peptide sequence is indicative of a coiled coil structure, which is a bundle of $\alpha$ helices wound into a superhelix stabilized by hydrophobic interactions between adjacent helices. ${ }^{115)}$ 
In addition to an $\mathrm{HR}$ region adjacent to the fusion peptide, called HR1 (residues 41-55), there is another HR region, called HR2 (residues 77-101), near the transmembrane domain (Fig. 7). In the resting state at neutral $\mathrm{pH}$, the hydrophobic fusion peptides are buried in the trimeric structure; HR1 and HR2 are distant from each other. Upon low $\mathrm{pH}$ activation, the fusion peptides are exposed and inserted into the cellular membrane; HR1 and HR2 undergo refolding that makes the helices bend to form a hairpin (formation of trimer-of-hairpins or a stable six-helix bundle) promoting viral and cellular membranes in proximity. These conformational rearrangements release Gibbs free energy, resulting in merger of the two membranes and ultimately pore formation. ${ }^{116), 117)}$

Near the cleavage site is a histidine-rich basic patch (Fig. 4), which contains HA1 residues His18 and His38 and HA2 residue His111. This basic patch is highly conserved in both human and avian H1, $\mathrm{H} 2$ and $\mathrm{H} 5 \mathrm{HA}$ sequences. The patch has a $\mathrm{pH}-$ sensitive property and has been proposed to destabilize the HA interface, allowing exposure of the fusion peptide. ${ }^{118)}$ At acidic $\mathrm{pH}$ lower than the $\mathrm{pKa}$ of His, His becomes protonated and the positively charged His can be strong enough to push HA apart, resulting in release of the fusion peptide in the endosome and rearrangement of HA structure leading to its insertion into the endosomal membrane. ${ }^{118), 119)}$

Another basic patch is found within the vestigial esterase domain at the base of the HA1 globular domain (Fig. 4). The 1918 HA1 contains four histidines (His47, His275, His285 and His298) and one lysine (Lys50) in this basic patch. His47, His298 and Lys50 are observed in other H1 HAs. His285 has been replaced by a neutral residue, either Leu or Gln, in the seasonal $\mathrm{H} 1$ viruses since the first seasonal $\mathrm{H} 1$ isolate in 1934, whereas His275 has been substituted with an acidic residue, Asp, in the seasonal $\mathrm{H} 1$ viruses since 1950. The novel pandemic (H1N1) 2009 HA has His47, His275, the basic Lys285 instead of His285, His298, Lys50 and additional Lys46. ${ }^{29)}$ The 2009 HA also has an extra $N$-glycosylation site at 278-280 (NTT) near the second basic patch region and near the $\mathrm{Cb}$ antigenic site, and it has thus been proposed that glycosylation at this site might prevent access of basic enzymes to the basic patch region and possibly interfere with recognition of antibodies. ${ }^{29)}$ The presence of a larger basic patch in HA is believed to enhance the process of virus membrane fusion and subsequent infectivity. ${ }^{118), 120)}$

\section{Conclusions}

Much progress has been achieved in studies on the HA of influenza A viruses, and the results have provided a foundation for understanding the roles of HA in antigenic variation, host range and membrane fusion in viral entry. However, some key questions have not been answered yet. For example, exactly how a new pandemic strain arises remains unknown. It is not known why the 2009 swine-origin H1N1 virus became pandemic (worldwide geographic distribution in human populations), while other swine viruses, including its individual parent viruses (North American and Eurasian swine viruses) did not become pandemic even though the swine viruses are known to be occasionally transmitted directly from pigs to humans. Several factors, such as $\mathrm{HA},{ }^{121)}$ $\mathrm{PB}^{122)}$ and NA, ${ }^{121)}$ may be involved in the evolution of a pandemic influenza virus strain. Little research has been performed to reveal the possibility that a nonhuman influenza virus must acquire mutations to recognize long $\alpha 2-6$ sialylated glycans for efficient transmission in human populations to become pandemic. Recently, North American swine influenza virus isolates have been demonstrated to bind to long $\alpha$ 2-6-linked receptors similar to receptor binding profiles of early human pandemic $2009 \mathrm{H} 1 \mathrm{~N} 1$ isolates and past seasonal H1N1 isolates. ${ }^{70)}$ Also, $N$-glycan analysis of cultured cells of primary swine respiratory epithelial cells (SRECs) revealed the presence of long $\alpha 2-6$ receptors in SRECs, ${ }^{49)}$ not only in human bronchial epithelial cells. ${ }^{69)}$ Thus, further analysis of the sequences of glycans expressed on animal host tissues and more experiments on glycan arrays under more closely approximated natural conditions in conjunction with structural analysis of influenza virus HA binding or in vivo receptor binding experiments will undoubtedly lead to an understanding of glycan binding features of influenza virus HAs and changes in influenza HA that lead to changes in influenza host range. Lessons from the two past pandemics in 1957 and 1968 that emerged from reassortment between human and low pathogenic avian influenza viruses must be learned for strengthening surveillance of and response to emergence of new reassortant strains, especially between the novel H1N1 virus rapidly spreading among humans ${ }^{123)}$ and being the dominant influenza strain in most regions of the world today ${ }^{124)}$ and the highly pathogenic avian influenza $\mathrm{H} 5 \mathrm{~N} 1$ virus currently causing sporadic human infection with a high mortality rate. ${ }^{125)}$ Fusion mechanism is a model that needs to be 
verified experimentally. Further studies, such as sequencing coupled with bioinformatics, experimental analyses and the use of specific compounds with known actions, should uncover the mechanisms of antigenic variation of influenza viruses, the emergence of pandemic strains, receptor binding and fusion, leading to the development of novel vaccines and medicines for the prevention, control and therapy of influenza. Although several compounds have been reported to inhibit HA functions and virus infectivity, for example, glycopolymers carrying $N$-acetyllactosamine repeats ${ }^{83)}$ and $N$-(1-thia-4-azaspiro[4.5]decan-4-yl)carboxamide inhibitors ${ }^{126)}$ possessing HAmediated attachment and HA-mediated membrane fusion inhibitory activities, respectively, no clinical HA inhibitors are available at present. It is possible that improved and new anti-HA inhibitors will be developed in the near future for influenza therapies and may be applied together with anti-influenza drugs currently available, such as oseltamivir carboxylate (Tamiflu; NA inhibitor) and zanamivir (Relenza; NA inhibitor) and/or with other recently developed anti-influenza drugs, such as T-705 (favipiravir, viral RNA polymerase inhibitor), ${ }^{127}$ peramivir (long-acting NA inhibitor) ${ }^{128)}$ and laninamivir octanoate (long-acting NA inhibitor), ${ }^{129)}$ in order to enhance their efficiency and/or to reduce the rapid spread of drug-resistant influenza viruses as the consequence of error-prone replication of influenza viruses.

\section{References}

1) Johnson, N.P. and Mueller, J. (2002) Updating the accounts: global mortality of the 1918-1920 "Spanish" influenza pandemic. Bull. Hist. Med. 76, 105-115.

2) WHO (2010) Pandemic (H1N1) 2009 - update 112 (http://www.who.int/csr/don/2010_08_06/en/index. html).

3) Goldsmith, C. (2007) It's just the flu. In Influenza: The Next Pandemic? (ed. Goldsmith, C.). Twenty-First Century Books, Minneapolis, pp. $7-20$.

4) Munster, V.J., Baas, C., Lexmond, P., Waldenstrom, J., Wallensten, A., Fransson, T., Rimmelzwaan, G.F., Beyer, W.E., Schutten, M., Olsen, B., Osterhaus, A.D. and Fouchier, R.A. (2007) Spatial, temporal, and species variation in prevalence of influenza A viruses in wild migratory birds. PLoS Pathog. 3, e61 (doi:10.1371/ journal.ppat.0030061).

5) Peacey, M., Hall, R.J., Sonnberg, S., Ducatez, M., Paine, S., Nicol, M., Ralston, J.C. Bandaranayake, D., Hope, V., Webby, R.J. and Huang, S. (2010) Pandemic (H1N1) 2009 and seasonal influenza A (H1N1) co-infection, New Zealand, 2009. Emerg. Infect. Dis. 16, 1618-1620.

6) Liu, W., Li, Z.D., Tang, F., Wei, M.T., Tong, Y.G., Zhang, L., Xin, Z.T., Ma, M.J., Zhang, X.A., Liu, L.J., Zhan, L., He, C., Yang, H., Boucher, C.A., Richardus, J.H. and Cao, W.C. (2010) Mixed infections of pandemic H1N1 and seasonal H3N2 viruses in 1 outbreak. Clin. Infect. Dis. 50, 13591365.

7) Wise, H.M., Foeglein, A., Sun, J., Dalton, R.M., Patel, S., Howard, W., Anderson, E.C., Barclay, W.S. and Digard, P. (2009) A complicated message: Identification of a novel PB1-related protein translated from influenza A virus segment 2 mRNA. J. Virol. 83, 8021-8031.

8) Le Goffic, R., Bouguyon, E., Chevalier, C., Vidic, J., Da Costa, B., Leymarie, O., Bourdieu, C., Decamps, L., Dhorne-Pollet, S. and Delmas, B. (2010) Influenza A virus protein PB1-F2 exacerbates IFN- $\beta$ expression of human respiratory epithelial cells. J. Immunol. 185, 4812-4823.

9) Hatada, E. and Fukuda, R. (1992) Binding of influenza A virus NS1 protein to dsRNA in vitro. J. Gen. Virol. 73, 3325-3329.

10) Hale, B.G., Randall, R.E., Ortin, J. and Jackson, D. (2008) The multifunctional NS1 protein of influenza A viruses. J. Gen. Virol. 89, 2359-2376.

11) Chen, J., Huang, S. and Chen, Z. (2011) Human cellular protein nucleoporin hNup98 interacts with influenza A virus NS2/nuclear export protein and overexpression of its GLFG repeat domain can inhibit virus propagation. J. Gen. Virol. 91, 2474-2484.

12) Odagiri, T. and Tobita, K. (1990) Mutation in NS2, a nonstructural protein of influenza A virus, extragenically causes aberrant replication and expression of the PA gene and leads to generation of defective interfering particles. Proc. Natl. Acad. Sci. U.S.A. 87, 5988-5992.

13) Nayak, D.P., Hui, E.K. and Barman, S. (2004) Assembly and budding of influenza virus. Virus Res. 106, 147-165.

14) Palese, P. and Schulman, J.L. (1976) Mapping of the influenza virus genome: identification of the hemagglutinin and the neuraminidase genes. Proc. Natl. Acad. Sci. U.S.A. 73, 2142-2146.

15) Gething, M.J., McCammon, K. and Sambrook, J. (1986) Expression of wild-type and mutant forms of influenza hemagglutinin: the role of folding in intracellular transport. Cell 46, 939-950.

16) Braakman, I., Hoover-Litty, H., Wagner, K.R. and Helenius, A. (1991) Folding of influenza hemagglutinin in the endoplasmic reticulum. J. Cell Biol. 114, 401-411.

17) Copeland, C.S., Doms, R.W., Bolzau, E.M., Webster, R.G. and Helenius, A. (1986) Assembly of influenza hemagglutinin trimers and its role in intracellular transport. J. Cell Biol. 103, 11791191.

18) Laver, W.G. (1971) Separation of two polypeptide chains from the hemagglutinin subunit of influenza virus. Virology 45, 275-288. 
19) Isin, B., Doruker, P. and Bahar, I. (2002) Functional motions of influenza virus hemagglutinin: a structure-based analytical approach. Biophys. J. 82, 569-581.

20) Wiley, D.C. and Skehel, J.J. (1987) The structure and function of the hemagglutinin membrane glycoprotein of influenza virus. Annu. Rev. Biochem. 56, 365-394.

21) Wang, C.C., Chen, J.R., Tseng, Y.C., Hsu, C.H., Hung, Y.F., Chen, S.W., Chen, C.M., Khoo, K.H., Cheng, T.J., Cheng, Y.S., Jan, J.T., Wu, C.Y., Ma, C. and Wong, C.H. (2009) Glycans on influenza hemagglutinin affect receptor binding and immune response. Proc. Natl. Acad. Sci. U.S.A. 106, 18137-18142.

22) Liu, N., Wang, G., Lee, K.C., Guan, Y., Chen, H. and Cai, Z. (2009) Mutations in influenza virus replication and transcription: detection of amino acid substitutions in hemagglutinin of an avian influenza virus (H1N1). FASEB J. 23, 3377-3382.

23) McDonald, N.J., Smith, C.B. and Cox, N.J. (2007) Antigenic drift in the evolution of H1N1 influenza A viruses resulting from deletion of a single amino acid in the haemagglutinin gene. J. Gen. Virol. 88, 3209-3213.

24) Xu, R., Ekiert, D.C., Krause, J.C., Hai, R., Crowe, J.E. Jr. and Wilson, I.A. (2010) Structural basis of preexisting immunity to the $2009 \mathrm{H} 1 \mathrm{~N} 1$ pandemic influenza virus. Science 328, 357-360.

25) Zimmer, S.M. and Burke, D.S. (2009) Historical perspective-Emergence of influenza A (H1N1) viruses. N. Engl. J. Med. 361, 279-285.

26) Kendal, A.P., Noble, G.R., Skehel, J.J. and Dowdle, W.R. (1978) Antigenic similarity of influenza A (H1N1) viruses from epidemics in 1977-1978 to "Scandinavian" strains isolated in epidemics of 1950-1951. Virology 89, 632-636.

27) Neumann, G., Noda, T. and Kawaoka, Y. (2009) Emergence and pandemic potential of swine-origin H1N1 influenza virus. Nature 459, 931-939.

28) Garten, R.J., Davis, C.T., Russell, C.A., Shu, B., Lindstrom, S., Balish, A., Sessions, W.M., Xu, X., Skepner, E., Deyde, V., Okomo-Adhiambo, M., Gubareva, L., Barnes, J., Smith, C.B., Emery, S.L., Hillman, M.J., Rivailler, P., Smagala, J., de Graaf, M., Burke, D.F., Fouchier, R.A., Pappas, C., Alpuche-Aranda, C.M., Lopez-Gatell, H., Olivera, H., Lopez, I., Myers, C.A., Faix, D., Blair, P.J., Yu, C., Keene, K.M., Dotson, P.D. Jr., Boxrud, D., Sambol, A.R., Abid, S.H., St George, K., Bannerman, T., Moore, A.L., Stringer, D.J., Blevins, P., Demmler-Harrison, G.J., Ginsberg, M., Kriner, P., Waterman, S., Smole, S., Guevara, H.F., Belongia, E.A., Clark, P.A., Beatrice, S.T., Donis, R., Katz, J., Finelli, L., Bridges, C.B., Shaw, M., Jernigan, D.B., Uyeki, T.M., Smith, D.J., Klimov, A.I. and Cox, N.J. (2009) Antigenic and genetic characteristics of swine-origin 2009 $\mathrm{A}(\mathrm{H} 1 \mathrm{~N} 1)$ influenza viruses circulating in humans. Science 325, 197-201.

29) Zhang, W., Qi, J., Shi, Y., Li, Q., Gao, F., Sun, Y., Lu, X., Lu, Q., Vavricka, C.J., Liu, D., Yan, J. and Gao, G.F. (2010) Crystal structure of the swine-origin A (H1N1)-2009 influenza A virus hemagglutinin (HA) reveals similar antigenicity to that of the 1918 pandemic virus. Protein Cell 1, 459-467.

30) Raymond, F.L., Caton, A.J., Cox, N.J., Kendal, A.P. and Brownlee, G.G. (1986) The antigenicity and evolution of influenza H1 haemagglutinin, from 1950-1957 and 1977-1983: two pathways from one gene. Virology 148, 275-287.

31) Igarashi, M., Ito, K., Yoshida, R., Tomabechi, D., Kida, H. and Takada, A. (2010) Predicting the antigenic structure of the pandemic (H1N1) 2009 influenza virus hemagglutinin. PLoS ONE 5, e8553 (doi:8510.1371/journal.pone.0008553).

32) Nakajima, K., Desselberger, U. and Palese, P. (1978) Recent human influenza A (H1N1) viruses are closely related genetically to strains isolated in 1950. Nature 274, 334-339.

33) Medina, R.A., Manicassamy, B., Stertz, S., Seibert, C.W., Hai, R., Belshe, R.B., Frey, S.E., Basler, C.F., Palese, P. and Garcia-Sastre, A. (2010) Pandemic 2009 H1N1 vaccine protects against 1918 Spanish influenza virus. Nat. Commun. 1, 28.

34) Manicassamy, B., Medina, R.A., Hai, R., Tsibane, T., Stertz, S., Nistal-Villan, E., Palese, P., Basler, C.F. and Garcia-Sastre, A. (2010) Protection of mice against lethal challenge with 2009 H1N1 influenza A virus by 1918-like and classical swine H1N1 based vaccines. PLoS Pathog. 6, e1000745 (doi:1000710.1001371/journal.ppat.1000745).

35) Hinshaw, V.S., Webster, R.G., Bean, W.J., Downie, J. and Senne, D.A. (1983) Swine influenza-like viruses in turkeys: potential source of virus for humans? Science 220, 206-208.

36) Brown, I.H. (2000) The epidemiology and evolution of influenza viruses in pigs. Vet. Microbiol. 74, 29-46.

37) Shinde, V., Bridges, C.B., Uyeki, T.M., Shu, B., Balish, A., Xu, X., Lindstrom, S., Gubareva, L.V., Deyde, V., Garten, R.J., Harris, M., Gerber, S., Vagasky, S., Smith, F., Pascoe, N., Martin, K., Dufficy, D., Ritger, K., Conover, C., Quinlisk, P., Klimov, A., Bresee, J.S. and Finelli, L. (2009) Triple-reassortant swine influenza A (H1) in humans in the United States, 2005-2009. N. Engl. J. Med. 360, 2616-2625.

38) Rezza, G. (2004) Avian influenza: a human pandemic threat? J. Epidemiol. Community Health 58, 807-808.

39) Centers for disease control and prevention (CDC) (2010) Key facts about avian influenza (bird flu) and highly pathogenic avian influenza A (H5N1) virus (http://www.cdc.gov/flu/avian/gen-info/facts. htm).

40) Yu, H., Zhou, Y.J., Li, G.X., Zhang, G.H., Liu, H.L., Yan, L.P., Liao, M. and Tong, G.Z. (2009) Further evidence for infection of pigs with human-like H1N1 influenza viruses in China. Virus Res. 140, 85-90.

41) Scholtissek, C., Burger, H., Bachmann, P.A. and 
Hannoun, C. (1983) Genetic relatedness of hemagglutinins of the $\mathrm{H} 1$ subtype of influenza A viruses isolated from swine and birds. Virology 129, 521-523.

42) Schulze, I.T. (1997) Effects of glycosylation on the properties and functions of influenza virus hemagglutinin. J. Infect. Dis. 176, S24-S28.

43) Mullick, J., Cherian, S.S., Potdar, V.A., Chadha, M.S. and Mishra, A.C. (2011) Evolutionary dynamics of the influenza A pandemic (H1N1) 2009 virus with emphasis on Indian isolates: evidence for adaptive evolution in the HA gene. Infect. Genet. Evol. 11, 997-1005.

44) Gottschalk, A. (1959) Chemistry of virus receptors. In The Viruses; Biochemical, Biological And Biophysical Properties (eds. Burnet, F.M. and Stanley, W.M.). Academic Press, New York, pp. 51-61.

45) Suzuki, Y., Matsunaga, M. and Matsumoto, M. (1985) N-Acetylneuraminyllactosylceramide, GM3-NeuAc, a new influenza A virus receptor which mediates the adsorption-fusion process of viral infection. Binding specificity of influenza virus $\mathrm{A} / \mathrm{Aichi} / 2 / 68$ (H3N2) to membrane-associated GM3 with different molecular species of sialic acid. J. Biol. Chem. 260, 1362-1365.

46) Wang, B. and Brand-Miller, J. (2003) The role and potential of sialic acid in human nutrition. Eur. J. Clin. Nutr. 57, 1351-1369.

47) Varki, A. and Schauer, R. (2009) Sialic acids. In Essentials of Glycobiology (eds. Varki, A., Cummings, R., Esko, J., Freeze, H., Stanley, P., Bertozzi, C.R., Hart, G.W. and Etzler, M.E.). Cold Spring Harbor Laboratory Press, New York, pp. 199-217.

48) Sriwilaijaroen, N., Kondo, S., Yagi, H., Takemae, N., Saito, T., Hiramatsu, H., Kato, K. and Suzuki, Y. (2011) $N$-glycans from porcine trachea and lung: predominant NeuAc $\alpha 2-6 \mathrm{Gal}$ could be a selective pressure for influenza variants in favor of human-type receptor. PLoS ONE 6, e16302 (doi:16310.11371/journal.pone.0016302).

49) Bateman, A.C., Karamanska, R., Busch, M.G., Dell, A., Olsen, C.W. and Haslam, S.M. (2010) Glycan analysis and influenza A virus infection of primary swine respiratory epithelial cells: the importance of NeuAc $\alpha 2-6$ glycans. J. Biol. Chem. 285, 34016-34026.

50) Matrosovich, M.N., Klenk, H.D. and Kawaoka, Y. (2006) Receptor specificity, host-range, and pathogenicity of influenza viruses. In Influenza Virology: Current Topics (ed. Kawaoka, Y.). Caister Academic Press, Wymondham, pp. 95137.

51) Suzuki, Y., Ito, T., Suzuki, T., Holland, R.E. Jr., Chambers, T.M., Kiso, M., Ishida, H. and Kawaoka, Y. (2000) Sialic acid species as a determinant of the host range of influenza A viruses. J. Virol. 74, 11825-11831.

52) Bardor, M., Nguyen, D.H., Diaz, S. and Varki, A. (2005) Mechanism of uptake and incorporation of the non-human sialic acid $N$-glycolylneuraminic acid into human cells. J. Biol. Chem. 280, 42284237.

53) Irie, A., Koyama, S., Kozutsumi, Y., Kawasaki, T. and Suzuki, A. (1998) The molecular basis for the absence of $N$-glycolylneuraminic acid in humans. J. Biol. Chem. 273, 15866-15871.

54) Martin, M.J., Rayner, J.C., Gagneux, P., Barnwell, J.W. and Varki, A. (2005) Evolution of humanchimpanzee differences in malaria susceptibility: relationship to human genetic loss of $\mathrm{N}$-glycolylneuraminic acid. Proc. Natl. Acad. Sci. U.S.A. 102, 12819-12824.

55) Suzuki, Y., Nagao, Y., Kato, H., Matsumoto, M., Nerome, K., Nakajima, K. and Nobusawa, E. (1986) Human influenza A virus hemagglutinin distinguishes sialyloligosaccharides in membraneassociated gangliosides as its receptor which mediates the adsorption and fusion processes of virus infection. Specificity for oligosaccharides and sialic acids and the sequence to which sialic acid is attached. J. Biol. Chem. 261, 17057-17061.

56) Ito, T., Couceiro, J.N., Kelm, S., Baum, L.G., Krauss, S., Castrucci, M.R., Donatelli, I., Kida, H., Paulson, J.C., Webster, R.G. and Kawaoka, Y. (1998) Molecular basis for the generation in pigs of influenza A viruses with pandemic potential. J. Virol. 72, 7367-7373.

57) Rogers, G.N., Pritchett, T.J., Lane, J.L. and Paulson, J.C. (1983) Differential sensitivity of human, avian, and equine influenza A viruses to a glycoprotein inhibitor of infection: selection of receptor specific variants. Virology 131, 394-408.

58) Baum, L.G. and Paulson, J.C. (1990) Sialyloligosaccharides of the respiratory epithelium in the selection of human influenza virus receptor specificity. Acta Histochem. Suppl. 40, 35-38.

59) Shinya, K., Ebina, M., Yamada, S., Ono, M., Kasai, N. and Kawaoka, Y. (2006) Avian flu: influenza virus receptors in the human airway. Nature 440, $435-436$.

60) Guo, C.T., Takahashi, N., Yagi, H., Kato, K., Takahashi, T., Yi, S.Q., Chen, Y., Ito, T., Otsuki, K., Kida, H., Kawaoka, Y., Hidari, K.I., Miyamoto, D., Suzuki, T. and Suzuki, Y. (2007) The quail and chicken intestine have sialylgalactose sugar chains responsible for the binding of influenza A viruses to human type receptors. Glycobiology 17, 713-724.

61) Wan, H. and Perez, D.R. (2006) Quail carry sialic acid receptors compatible with binding of avian and human influenza viruses. Virology 346, 278286.

62) Kuchipudi, S.V., Dunham, S.P., Nelli, R., White, G.A., Coward, V.J., Slomka, M.J., Brown, I.H. and Chang, K.C. (2011) Rapid death of duck cells infected with influenza: a potential mechanism for host resistance to H5N1. Immunol. Cell Biol. 90, 116-123.

63) Ito, T., Suzuki, Y., Suzuki, T., Takada, A., Horimoto, T., Wells, K., Kida, H., Otsuki, K., Kiso, M., Ishida, H. and Kawaoka, Y. (2000) Recognition of $\mathrm{N}$-glycolylneuraminic acid linked 
to galactose by the $\alpha 2,3$ linkage is associated with intestinal replication of influenza A virus in ducks. J. Virol. 74, 9300-9305.

64) Sriwilaijaroen, N., Kondo, S., Yagi, H., Wilairat, P., Hiramatsu, H., Ito, M., Ito, Y., Kato, K. and Suzuki, Y. (2009) Analysis of $N$-glycans in embryonated chicken egg chorioallantoic and amniotic cells responsible for binding and adaptation of human and avian influenza viruses. Glycoconj. J. 26, 433-443.

65) Takemae, N., Ruttanapumma, R., Parchariyanon, S., Yoneyama, S., Hayashi, T., Hiramatsu, H., Sriwilaijaroen, N., Uchida, Y., Kondo, S., Yagi, H., Kato, K., Suzuki, Y. and Saito, T. (2010) Alterations in receptor-binding properties of swine influenza viruses of the $\mathrm{H} 1$ subtype after isolation in embryonated chicken eggs. J. Gen. Virol. 91, 938-948.

66) Wu, W. and Air, G.M. (2004) Binding of influenza viruses to sialic acids: reassortant viruses with $\mathrm{A} /$ NWS/33 hemagglutinin bind to $\alpha 2,8$-linked sialic acid. Virology 325, 340-350.

67) Childs, R.A., Palma, A.S., Wharton, S. Matrosovich, T., Liu, Y., Chai, W., CampaneroRhodes, M.A., Zhang, Y., Eickmann, M., Kiso, M., Hay, A., Matrosovich, M. and Feizi, T. (2009) Receptor-binding specificity of pandemic influenza A (H1N1) 2009 virus determined by carbohydrate microarray. Nat. Biotechnol. 27, 797-799.

68) Stevens, J., Blixt, O., Glaser, L., Taubenberger, J.K., Palese, P., Paulson, J.C. and Wilson, I.A. (2006) Glycan microarray analysis of the hemagglutinins from modern and pandemic influenza viruses reveals different receptor specificities. J. Mol. Biol. 355, 1143-1155.

69) Chandrasekaran, A., Srinivasan, A., Raman, R., Viswanathan, K., Raguram, S., Tumpey, T.M., Sasisekharan, V. and Sasisekharan, R. (2008) Glycan topology determines human adaptation of avian H5N1 virus hemagglutinin. Nat. Biotechnol. 26, 107-113.

70) Bradley, K.C., Jones, C.A., Tompkins, S.M., Tripp, R.A., Russell, R.J., Gramer, M.R., HeimburgMolinaro, J., Smith, D.F., Cummings, R.D. and Steinhauer, D.A. (2011) Comparison of the receptor binding properties of contemporary swine isolates and early human pandemic H1N1 isolates (Novel 2009 H1N1). Virology 413, 169-182.

71) Gamblin, S.J., Haire, L.F., Russell, R.J., Stevens, D.J., Xiao, B., Ha, Y., Vasisht, N., Steinhauer, D.A., Daniels, R.S., Elliot, A., Wiley, D.C. and Skehel, J.J. (2004) The structure and receptor binding properties of the 1918 influenza hemagglutinin. Science 303, 1838-1842.

72) Tumpey, T.M., Maines, T.R., Van Hoeven, N., Glaser, L., Solorzano, A., Pappas, C., Cox, N.J., Swayne, D.E., Palese, P., Katz, J.M. and GarciaSastre, A. (2007) A two-amino acid change in the hemagglutinin of the 1918 influenza virus abolishes transmission. Science 315, 655-659.

73) Matrosovich, M.N., Gambaryan, A.S., Teneberg, S., Piskarev, V.E., Yamnikova, S.S., Lvov, D.K.,
Robertson, J.S. and Karlsson, K.A. (1997) Avian influenza A viruses differ from human viruses by recognition of sialyloligosaccharides and gangliosides and by a higher conservation of the HA receptor-binding site. Virology 233, 224-234.

74) Reid, A.H., Fanning, T.G., Hultin, J.V. and Taubenberger, J.K. (1999) Origin and evolution of the 1918 "Spanish" influenza virus hemagglutinin gene. Proc. Natl. Acad. Sci. U.S.A. 96, 16511656.

75) Leigh, M.W., Connor, R.J., Kelm, S., Baum, L.G. and Paulson, J.C. (1995) Receptor specificity of influenza virus influences severity of illness in ferrets. Vaccine 13, 1468-1473.

76) Srinivasan, A., Viswanathan, K., Raman, R., Chandrasekaran, A., Raguram, S., Tumpey, T.M., Sasisekharan, V. and Sasisekharan, R. (2008) Quantitative biochemical rationale for differences in transmissibility of 1918 pandemic influenza A viruses. Proc. Natl. Acad. Sci. U.S.A. 105, 2800-2805.

77) Gambaryan, A.S., Tuzikov, A.B., Piskarev, V.E., Yamnikova, S.S., Lvov, D.K., Robertson, J.S., Bovin, N.V. and Matrosovich, M.N. (1997) Specification of receptor-binding phenotypes of influenza virus isolates from different hosts using synthetic sialylglycopolymers: non-egg-adapted human H1 and H3 influenza A and influenza $\mathrm{B}$ viruses share a common high binding affinity for $6^{\prime}-\operatorname{sialyl}(N$-acetyllactosamine). Virology 232, 345-350.

78) Gambaryan, A.S., Robertson, J.S. and Matrosovich, M.N. (1999) Effects of egg-adaptation on the receptor-binding properties of human influenza $\mathrm{A}$ and B viruses. Virology 258, 232-239.

79) Matrosovich, M., Tuzikov, A., Bovin, N., Gambaryan, A., Klimov, A., Castrucci, M.R., Donatelli, I. and Kawaoka, Y. (2000) Early alterations of the receptor-binding properties of $\mathrm{H} 1, \mathrm{H} 2$, and $\mathrm{H} 3$ avian influenza virus hemagglutinins after their introduction into mammals. J. Virol. 74, 8502-8512.

80) Soundararajan, V., Tharakaraman, K., Raman, R., Raguram, S., Shriver, Z., Sasisekharan, V. and Sasisekharan, R. (2009) Extrapolating from sequence - the $2009 \mathrm{H} 1 \mathrm{N1}$ 'swine' influenza virus. Nat. Biotechnol. 27, 510-513.

81) Maines, T.R., Jayaraman, A., Belser, J.A., Wadford, D.A., Pappas, C., Zeng, H., Gustin, K.M., Pearce, M.B., Viswanathan, K., Shriver, Z.H., Raman, R., Cox, N.J., Sasisekharan, R., Katz, J.M. and Tumpey, T.M. (2009) Transmission and pathogenesis of swine-origin $2009 \mathrm{~A}(\mathrm{H} 1 \mathrm{~N} 1)$ influenza viruses in ferrets and mice. Science 325, 484-487.

82) de Vries, R.P., de Vries, E., Moore, K.S., Rigter, A., Rottier, P.J. and de Haan, C.A. (2011) Only two residues are responsible for the dramatic difference in receptor binding between swine and new pandemic H1 hemagglutinin. J. Biol. Chem. 286, 5868-5875.

83) Hidari, K.I., Murata, T., Yoshida, K., Takahashi, 
Y., Minamijima, Y.H., Miwa, Y., Adachi, S., Ogata, M., Usui, T., Suzuki, Y. and Suzuki, T. (2008) Chemoenzymatic synthesis, characterization, and application of glycopolymers carrying lactosamine repeats as entry inhibitors against influenza virus infection. Glycobiology 18, 779788.

84) Chu, V.C. and Whittaker, G.R. (2004) Influenza virus entry and infection require host cell $N$-linked glycoprotein. Proc. Natl. Acad. Sci. U.S.A. 101, 18153-18158.

85) Yang, H., Carney, P. and Stevens, J. (2010) Structure and receptor binding properties of a pandemic H1N1 virus hemagglutinin. PLoS Curr. 2, RRN1152 (doi: 1110.1371/currents.RRN1152).

86) Ledesma, J., Pozo, F., Ruiz, M.P., Navarro, J.M., Pineiro, L., Montes, M., Castro, S.P., Fernandez, J.S., Costa, J.G., Fernandez, M., Galan, J.C., Cuevas, M.T., Casas, I. and Brena, P.P. (2011) Substitutions in position 222 of haemagglutinin of pandemic influenza A (H1N1) 2009 viruses in Spain. J. Clin. Virol. 51, 75-78.

87) Valli, M.B., Selleri, M., Meschi, S., Zaccaro, P., Vincenti, D., Lalle, E., Capobianchi, M.R. and Menzo, S. (2011) Hemagglutinin 222 variants in pandemic (H1N1) 2009 virus. Emerg. Infect. Dis. 17, 749-751.

88) Chutinimitkul, S., Herfst, S., Steel, J., Lowen, A.C. Ye, J., van Riel, D., Schrauwen, E.J., Bestebroer, T.M., Koel, B., Burke, D.F., Sutherland-Cash, K.H., Whittleston, C.S., Russell, C.A., Wales, D.J., Smith, D.J., Jonges, M., Meijer, A., Koopmans, M., Rimmelzwaan, G.F., Kuiken, T., Osterhaus, A.D., Garcia-Sastre, A., Perez, D.R. and Fouchier, R.A. (2011) Virulence-associated substitution D222G in the hemagglutinin of 2009 pandemic influenza $\mathrm{A}(\mathrm{H} 1 \mathrm{~N} 1)$ virus affects receptor binding. J. Virol. 84, 11802-11813.

89) Lin, T., Wang, G., Li, A., Zhang, Q., Wu, C., Zhang, R., Cai, Q., Song, W. and Yuen, K.Y. (2009) The hemagglutinin structure of an avian H1N1 influenza A virus. Virology 392, 73-81.

90) Qi, L., Kash, J.C., Dugan, V.G., Wang, R., Jin, G., Cunningham, R.E. and Taubenberger, J.K. (2009) Role of sialic acid binding specificity of the 1918 influenza virus hemagglutinin protein in virulence and pathogenesis for mice. J. Virol. 83, 3754-3761.

91) Gamblin, S.J. and Skehel, J.J. (2010) Influenza hemagglutinin and neuraminidase membrane glycoproteins. J. Biol. Chem. 285, 28403-28409.

92) Couceiro, J.N., Paulson, J.C. and Baum, L.G. (1993) Influenza virus strains selectively recognize sialyloligosaccharides on human respiratory epithelium; the role of the host cell in selection of hemagglutinin receptor specificity. Virus Res. 29, 155-165.

93) Marinina, V.P., Gambarian, A.S., Bovin, N.V., Tuzikov, A.B., Shilov, A.A., Sinitsyn, B.V. and Matrosovich, M.N. (2003) The effect of losing glycosylation sites near the receptor-binding region on the receptor phenotype of the human influenza virus H1N1. Mol. Biol. 37, 468-472.

94) Schwarzer, J., Rapp, E., Hennig, R., Genzel, Y., Jordan, I., Sandig, V. and Reichl, U. (2009) Glycan analysis in cell culture-based influenza vaccine production: influence of host cell line and virus strain on the glycosylation pattern of viral hemagglutinin. Vaccine 27, 4325-4336.

95) Romanova, J., Katinger, D., Ferko, B., Voglauer, R., Mochalova, L., Bovin, N., Lim, W., Katinger, H. and Egorov, A. (2003) Distinct host range of influenza H3N2 virus isolates in Vero and MDCK cells is determined by cell specific glycosylation pattern. Virology 307, 90-97.

96) Mir-Shekari, S.Y., Ashford, D.A., Harvey, D.J., Dwek, R.A. and Schulze, I.T. (1997) The glycosylation of the influenza A virus hemagglutinin by mammalian cells. A site-specific study. J. Biol. Chem. 272, 4027-4036.

97) Reichert, T., Chowell, G., Nishiura, H., Christensen, R. and McCullers, J. (2010) Does glycosylation as a modifier of original antigenic sin explain the case age distribution and unusual toxicity in pandemic novel H1N1 influenza? BMC Infect. Dis. 10, 5 .

98) Harrison, S.C. (2008) Viral membrane fusion. Nat. Struct. Mol. Biol. 15, 690-698.

99) Steinhauer, D.A. (1999) Role of hemagglutinin cleavage for the pathogenicity of influenza virus. Virology 258, 1-20.

100) Zhirnov, O.P., Ikizler, M.R. and Wright, P.F. (2002) Cleavage of influenza a virus hemagglutinin in human respiratory epithelium is cell associated and sensitive to exogenous antiproteases. J. Virol. 76, 8682-8689.

101) Taubenberger, J.K. (1998) Influenza virus hemagglutinin cleavage into HA1, HA2: no laughing matter. Proc. Natl. Acad. Sci. U.S.A. 95, 97139715.

102) Horimoto, T. and Kawaoka, Y. (2005) Influenza: lessons from past pandemics, warnings from current incidents. Nat. Rev. Microbiol. 3, 591600 .

103) Walker, J.A., Molloy, S.S., Thomas, G., Sakaguchi, T., Yoshida, T., Chambers, T.M. and Kawaoka, Y. (1994) Sequence specificity of furin, a proprotein-processing endoprotease, for the hemagglutinin of a virulent avian influenza virus. J. Virol. 68, $1213-1218$

104) Capua, I. and Alexander, D.J. (2004) Avian influenza: recent developments. Avian Pathol. 33, 393-404.

105) Chen, J., Lee, K.H., Steinhauer, D.A., Stevens, D.J., Skehel, J.J. and Wiley, D.C. (1998) Structure of the hemagglutinin precursor cleavage site, a determinant of influenza pathogenicity and the origin of the labile conformation. Cell 95, 409417.

106) Cross, K.J., Langley, W.A., Russell, R.J., Skehel, J.J. and Steinhauer, D.A. (2009) Composition and functions of the influenza fusion peptide. Protein Pept. Lett. 16, 766-778.

107) Pécheur, E.I., Sainte-Marie, J., Bienvenüe, A. and Hoekstra, D. (1999) Peptides and membrane 
fusion: towards an understanding of the molecular mechanism of protein-induced fusion. J. Membr. Biol. 167, 1-17.

108) Garten, W., Bosch, F.X., Linder, D., Rott, R. and Klenk, H.D. (1981) Proteolytic activation of the influenza virus hemagglutinin: The structure of the cleavage site and the enzymes involved in cleavage. Virology 115, 361-374.

109) Cross, K.J., Wharton, S.A., Skehel, J.J., Wiley, D.C. and Steinhauer, D.A. (2001) Studies on influenza haemagglutinin fusion peptide mutants generated by reverse genetics. EMBO J. 20, 44324442.

110) Qiao, H., Armstrong, R.T., Melikyan, G.B., Cohen, F.S. and White, J.M. (1999) A specific point mutant at position 1 of the influenza hemagglutinin fusion peptide displays a hemifusion phenotype. Mol. Biol. Cell 10, 2759-2769.

111) Gething, M.J., Doms, R.W., York, D. and White, J. (1986) Studies on the mechanism of membrane fusion: site-specific mutagenesis of the hemagglutinin of influenza virus. J. Cell Biol. 102, 11-23.

112) Li, Y., Han, X., Lai, A.L., Bushweller, J.H., Cafiso, D.S. and Tamm, L.K. (2005) Membrane structures of the hemifusion-inducing fusion peptide mutant G1S and the fusion-blocking mutant G1V of influenza virus hemagglutinin suggest a mechanism for pore opening in membrane fusion. J. Virol. 79, 12065-12076.

113) Steinhauer, D.A., Wharton, S.A., Skehel, J.J. and Wiley, D.C. (1995) Studies of the membrane fusion activities of fusion peptide mutants of influenza virus hemagglutinin. J. Virol. 69, $6643-6651$.

114) Lai, A.L. and Tamm, L.K. (2007) Locking the kink in the influenza hemagglutinin fusion domain structure. J. Biol. Chem. 282, 23946-23956.

115) Chambers, P., Pringle, C.R. and Easton, A.J. (1990) Heptad repeat sequences are located adjacent to hydrophobic regions in several types of virus fusion glycoproteins. J. Gen. Virol. 71 (Pt 12), 3075-3080.

116) Russell, C.J., Kantor, K.L., Jardetzky, T.S. and Lamb, R.A. (2003) A dual-functional paramyxovirus $\mathrm{F}$ protein regulatory switch segment: activation and membrane fusion. J. Cell Biol. 163, 363-374

117) Chang, D.K., Cheng, S.F., Kantchev, E.A., Lin, C.H. and Liu, Y.T. (2008) Membrane interaction and structure of the transmembrane domain of influenza hemagglutinin and its fusion peptide complex. BMC Biol. 6, 2 .

118) Stevens, J., Corper, A.L., Basler, C.F., Taubenberger, J.K., Palese, P. and Wilson, I.A. (2004) Structure of the uncleaved human H1 hemagglutinin from the extinct 1918 influenza virus. Science 303, 1866-1870.

119) Kampmann, T., Mueller, D.S., Mark, A.E., Young, P.R. and Kobe, B. (2006) The Role of histidine residues in low-pH-mediated viral membrane fusion. Structure 14, 1481-1487.

120) Sun, Y., Shi, Y., Zhang, W., Li, Q., Liu, D.,
Vavricka, C., Yan, J. and Gao, G.F. (2010) In silico characterization of the functional and structural modules of the hemagglutinin protein from the swine-origin influenza virus A (H1N1)2009. Sci. China Life Sci. 53, 633-642.

121) Neumann, G. and Kawaoka, Y. (2006) Host range restriction and pathogenicity in the context of influenza pandemic. Emerg. Infect. Dis. 12, 881886.

122) Van Hoeven, N., Pappas, C., Belser, J.A., Maines, T.R., Zeng, H., Garcia-Sastre, A., Sasisekharan, R., Katz, J.M. and Tumpey, T.M. (2009) Human HA and polymerase subunit PB2 proteins confer transmission of an avian influenza virus through the air. Proc. Natl. Acad. Sci. U.S.A. 106, 33663371.

123) Settembre, E.C., Dormitzer, P.R. and Rappuoli, R. (2011) Learning from the 2009 H1N1 pandemic: prospects for more broadly effective influenza vaccines. J. Mol. Cell Biol. 3, 144-146.

124) WHO (2011) Global alert and response (GAR): Influenza update (http://www.who.int/csr/disease/ influenza/latest_update_GIP_surveillance/en/).

125) Van Kerkhove, M.D., Mumford, E., Mounts, A.W., Bresee, J., Ly, S., Bridges, C.B. and Otte, J. (2011) Highly pathogenic avian influenza (H5N1): pathways of exposure at the animal-human interface, a systematic review. PLoS ONE 6, e14582 (doi:14510.11371/journal.pone.0014582).

126) Vanderlinden, E., Goktas, F., Cesur, Z., Froeyen, M., Reed, M.L., Russell, C.J., Cesur, N. and Naesens, L. (2010) Novel inhibitors of influenza virus fusion: structure-activity relationship and interaction with the viral hemagglutinin. J. Virol. 84, 4277-4288.

127) Kiso, M., Takahashi, K., Sakai-Tagawa, Y., Shinya, K., Sakabe, S., Le, Q.M., Ozawa, M., Furuta, Y. and Kawaoka, Y. (2010) T-705 (favipiravir) activity against lethal H5N1 influenza A viruses. Proc. Natl. Acad. Sci. U.S.A. 107, 882-887.

128) Kohno, S., Kida, H., Mizuguchi, M., Hirotsu, N., Ishida, T., Kadota, J. and Shimada, J. (2011) Intravenous peramivir for treatment of influenza $A$ and $B$ virus infection in high-risk patients. Antimicrob. Agents Chemother. 55, 2803-2812.

129) Sugaya, N. and Ohashi, Y. (2010) Long-acting neuraminidase inhibitor laninamivir octanoate (CS-8958) versus oseltamivir as treatment for children with influenza virus infection. Antimicrob. Agents Chemother. 54, 2575-2582.

130) Liu, J., Stevens, D.J., Haire, L.F., Walker, P.A., Coombs, P.J., Russell, R.J., Gamblin, S.J. and Skehel, J.J. (2009) Structures of receptor complexes formed by hemagglutinins from the Asian Influenza pandemic of 1957. Proc. Natl. Acad. Sci. U.S.A. 106, 17175-17180.

131) Bullough, P.A., Hughson, F.M., Skehel, J.J. and Wiley, D.C. (1994) Structure of influenza haemagglutinin at the $\mathrm{pH}$ of membrane fusion. Nature 371, 37-43.

132) Shimizu, T., Takizawa, N., Watanabe, K., Nagata, K. and Kobayashi, N. (2010) Crucial role of the 
influenza virus NS2 (NEP) $C$-terminal domain in M1 binding and nuclear export of vRNP. FEBS Lett. 585, 41-46.

133) Martin, K. and Helenius, A. (1991) Nuclear transport of influenza virus ribonucleoproteins: the viral matrix protein (M1) promotes export and inhibits import. Cell 67, 117-130.

134) Chen, C.J., Chen, G.W., Wang, C.H., Huang, C.H., Wang, Y.C. and Shih, S.R. (2010) Differential localization and function of PB1-F2 derived from different strains of influenza A virus. J. Virol. 84, 10051-10062.

135) Ruigrok, R.W., Barge, A., Durrer, P., Brunner, J., Ma, K. and Whittaker, G.R. (2000) Membrane interaction of influenza virus M1 protein. Virology 267, 289-298.

(Received Aug. 3, 2011; accepted Mar. 30, 2012)

\section{Profile}

Nongluk Sriwilaijaroen was born in Suphanburi Province, Thailand, in 1974. After receiving her Ph.D. from the Department of Biochemistry, Faculty of Science, Mahidol University in 2004, she began as a lecturer in Graduate Studies, Faculty of Medicine, Thammasat University in 2005 and has been a lecturer in Preclinic since 2008. In 2007, she started to study influenza under the supervision of Prof. Yasuo Suzuki in College of Life and Health Sciences, Chubu University, Japan. Her research interests include biochemical and molecular biology of influenza viruses and their host cells with focus on alteration in the receptor binding of hemagglutinin and functions of neuraminidase and the development of new anti-influenza drugs.

\section{Profile}

Yasuo Suzuki was born in Hamamatsu, Japan in 1940. He published his first influenza work on "Sialyloligosaccharides in membrane-associated gangliosides as the receptor which mediates the adsorption and fusion processes of the virus infection" in J. Biol. Chem. in 1985, 1986. After this work, he became a full professor of University of Shizuoka School of Pharmaceutical Sciences (1989-2006). He served as dean of the Graduate School (1996-1998) and School (1998-2002) of Pharmaceutical Sciences, University of Shizuoka. He moved to Chubu University in 2006 as professor and director of Health Science Hills and Institute of Life and Health Sciences. His work gradually focused on key words such as (1) sugar chains, (2) viruses including influenza viruses, and (3) viral drug discovery. He is developing a new scientific field, virology fused with

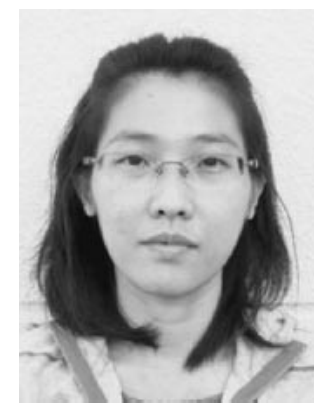
glycobiology, i.e., glycovirology. His recent work is focused on the molecular mechanism of host range variation of influenza viruses and initial glycovirological signals for the next influenza pandemic. He received The Pharmaceutical Society of Japan Award, 2004 and Chunichi Cultural Award, 2004.

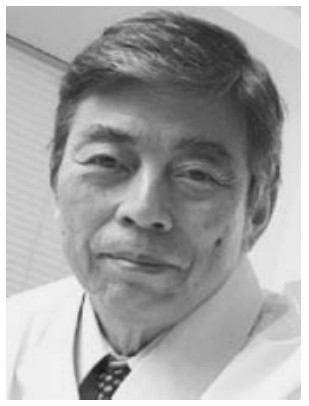

